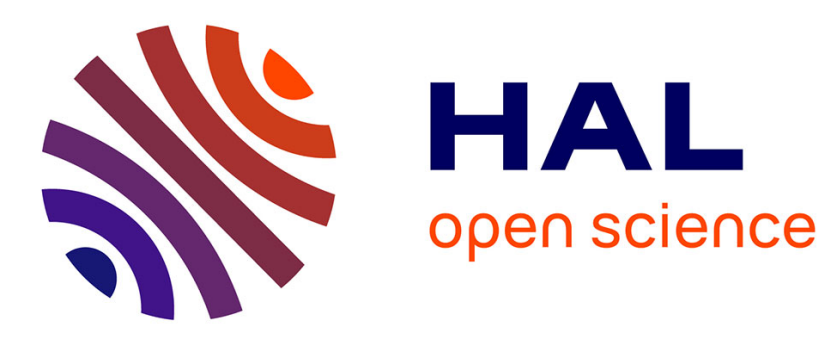

\title{
Cellular senescence as a possible link between prostate diseases of the ageing male
}

\author{
Gaelle Fiard, Vasilis Stavrinides, Emma S Chambers, Susan Heavey, Alex \\ Freeman, Rhys Ball, Arne N Akbar, Mark Emberton
}

\section{- To cite this version:}

Gaelle Fiard, Vasilis Stavrinides, Emma S Chambers, Susan Heavey, Alex Freeman, et al.. Cellular senescence as a possible link between prostate diseases of the ageing male. Nature Reviews Urology, In press, 10.1038/s41585-021-00496-8 . hal-03313022

\section{HAL Id: hal-03313022 \\ https://hal.science/hal-03313022}

Submitted on 3 Aug 2021

HAL is a multi-disciplinary open access archive for the deposit and dissemination of scientific research documents, whether they are published or not. The documents may come from teaching and research institutions in France or abroad, or from public or private research centers.
L'archive ouverte pluridisciplinaire HAL, est destinée au dépôt et à la diffusion de documents scientifiques de niveau recherche, publiés ou non, émanant des établissements d'enseignement et de recherche français ou étrangers, des laboratoires publics ou privés. 


\section{Cellular senescence as a possible link between prostate diseases of the ageing male}

Gaelle Fiard ${ }^{1,2,3}$, Vasilis Stavrinides ${ }^{1}$, Emma S Chambers ${ }^{4}$, Susan Heavey ${ }^{1}$, Alex Freeman ${ }^{6}$, Rhys Ball ${ }^{6}$, Arne N. Akbar ${ }^{5}$ and Mark Emberton ${ }^{1}$

${ }^{1}$ UCL Division of Surgery \& Interventional Science, University College London, London, UK

2 Department of Urology, Grenoble Alpes University Hospital, Grenoble, France

${ }^{3}$ Univ. Grenoble Alpes, CNRS, Grenoble INP, TIMC-IMAG, 38000 Grenoble, France

${ }^{4}$ Centre for Immunobiology, Blizard Institute, Queen Mary University of London, 4 Newark Street, London, UK

${ }^{5}$ Division of Medicine, The Rayne Building, 5 University Street, University College London, London, UK

${ }^{6}$ Department of Pathology, University College London Hospitals NHS Foundation Trust, London, UK

\section{Competing interests}

The authors declare no competing interests

Abstract | Senescent cells accumulate with age in all tissues. Although senescent cells undergo cell-cycle arrest, these cells remain metabolically active and their secretome known as senescence-associated secretory phenotype (SASP) - is responsible for a systemic pro-inflammatory state, which contributes to an inflammatory microenvironment. Senescent cells can be found in the ageing prostate and the SASP and can be linked to benign prostatic hyperplasia and prostate cancer. Indeed, a number of signalling pathways provide biological plausibility for the role of senescence in both BPH and prostate cancer, although proving causality is difficult. The theory of senescence as a mechanism for prostate disease has a number of clinical implications, and could offer opportunities for targetting in the future.

\section{Introduction}

Benign prostatic hyperplasia (BPH) and prostate cancer are two common disorders affecting the prostate and both share an increased incidence with advancing age. Autopsy studies 
have shown that up to $80 \%$ of men over 80 years of age develop prostatic enlargement or harbour prostate cancer cells, supporting the fact that almost all ageing men will at some point be affected by either one or both conditions ${ }^{1-3}$.

The prostate gland is an accessory male sex gland located around the urethra that is responsible for the synthesis of essential elements of semen. The zonal anatomy of the prostate, first published by John McNeal in 1981, describes four distinct areas ${ }^{4}$. The peripheral zone, which is present from birth, represents $\sim 70 \%$ of the volume of the glandular prostate and accounts for $\sim 70 \%$ of all prostate cancers ${ }^{5}$. The transition zone, which is wrapped around the prostatic urethra, is virtually nonexistent in pubertal boys, but agerelated growth progressively makes it the main component (around $60 \%$ based on MRI volumetry) of the prostate volume, laminating the peripheral zone, in adult men ${ }^{6}$. Less frequently, prostate cancer can arise from the much later developing transition zone, or from two zones also present from birth, the central zone and anterior fibromuscular stroma, although tumours arising in the fibromuscular stroma are most likely to develop from cells originating in either the peripheral zone or transition zone ${ }^{5}$. The mechanisms that initiate both BPH and cancer and drive progression remain poorly understood, although inflammation is emerging as a prominent driver of both pathologies ${ }^{7,8}$.

The ageing phenotype and many age-related diseases such as osteoarthritis and atherosclerosis have been linked to cellular senescence and the accumulation of senescent cells in tissues ${ }^{9}$. This replicative senescence, which was first described in 1961 by Hayflick and Moorhead, is a protective mechanism designed to stop the multiplication of cells with irreversible DNA damage ${ }^{10}$. Thus, senescence has been proposed to be a tumour suppression mechanism ${ }^{11}$. Senescent cells accumulate with age in all tissues studied ${ }^{12}$; although senescent cells are unable to replicate, they are metabolically active and secrete a raft of inflammatory mediators, which have been termed 'senescence-associated secretory phenotype (SASP)'. As a result, senescent cells are proposed to contribute to the phenomenon termed 'inflammageing', which is a state of chronic low-grade systemic inflammation observed in elderly animals and humans ${ }^{13}$. Furthermore, the accumulation of senescent cells leads to secondary events such as increased fibrosis, disorganised tissue architecture and, by extension, macroscopic modifications of organ structure and decreased 
organ function ${ }^{14,15}$. The exact role of senescent cells and the reason for their persistence throughout evolution remains unclear. However, several murine studies support the view that the removal of senescent cells, by agents termed 'senolytic' drugs, could result in prolonged lifespan and a reduction in age-related diseases ${ }^{16-19}$.

Cellular senescence and the inflammatory microenvironment surrounding senescent cells could provide an approach for the future treatment of two very common age-related prostate disorders. Thus, in this Review, we critically evaluate the existing knowledge regarding the role of cellular senescence in the pathogenesis of BPH and prostate cancer. We discuss the evidence that senescent cells can be found in the ageing prostate and consider how the SASP and inflammation can be linked to BPH and prostate cancer. Furthermore, we discuss possible signalling pathways that provide biological plausibility for the role of senescence in both $\mathrm{BPH}$ and prostate cancer and consider the clinical implications of these findings, highlighting the difficulties of proving causality and the grey areas in the field.

\section{Senescent cells in the ageing prostate}

The increased presence of senescent cells in ageing tissue has been demonstrated in many solid organs, and the amount of senescent cells has been linked to an ageing phenotype, most notably in the skin ${ }^{20,21}$. The identification of senescent cells, both in vitro and in vivo, was made possible by the development of several senescence biomarkers, and their application to prostate tissue confirmed the presence of senescent cells in the prostate.

\section{Biomarkers of senescence}

Although the mechanism of cellular senescence had been long known and studied in vitro, the actual presence of senescent cells in vivo was not confirmed in the skin until 1995 using a newly discovered senescence marker, senescence-associated $\beta$ galactosidase (SA- $\beta$ galactosidase) ${ }^{22}$. Other senescence markers have since been developed and new staining techniques used across various tissue types. 
Senescent cells are unable to replicate, typically blocked in the G1 phase of the cell cycle ${ }^{23}$. Consequently, one of the most commonly used senescence markers is p16 ${ }^{\text {INK4A }}$, a kinase involved in G1 phase cell cycle arrest, which is also known as cyclin-dependent kinase inhibitor 2A (CDKN2A $)^{21}$. Cathepsin D, a lysosomal protease, has also been proposed as a good marker of senescence, able to predict accurately the onset of cellular senescence after a variety of treatments ${ }^{24}$. Most senescence markers have been used and validated on skin specimens, thanks the availability of such tissue samples and visible ageing phenotype displayed, but studies have shown that the same markers can also be detected among other tissues such as prostatic, endothelial or skeletal muscle tissue ${ }^{16,20,21,25}$.

No senescence marker demonstrates perfect specificity and use of a combination of markers is advised to minimize false-positive or false-negative staining. For instance, SA- $\beta$ galactosidase expression is the consequence of an increased lysosomal activity, which can be due to senescence but can also be secondary to increased cell activity unrelated to senescence ${ }^{26}$. Co-staining should, therefore, be recommended with $\mathrm{Ki}-67$ to confirm the absence of cell proliferation, alongside a marker of senescence such as $\mathrm{p} 16^{\mathrm{INK} 4 \mathrm{~A}}$ or other novel biomarkers. Over the past 5 years, SA- $\beta$ galactosidase staining has benefitted from precise quantification methods and image visualization advances such as electron microscopy, which enable improved spatial resolution and structure identification ${ }^{27,28}$.

The ideal senescence biomarker to identify age-induced senescent cells would be one directed specifically at a senescence-specific feature rather than indirect effects of senescence, such as increased metabolic activity. A marker of telomere-associated DNA damage (TAF) has been used to detect and quantify senescent fibroblasts in the skin of young and aged healthy volunteers and could be a promising candidate as telomere shortening and dysfunction seem to have a prominent role in cellular senescence ${ }^{29}$. Likewise, the use of a gene panel has also been recommended for assessing therapy-induced senescence to minimize the risk of non-specific staining ${ }^{30}$.

\section{Evidence of senescence in the prostate}


Defining reliable biomarkers that detect senescence in human prostate tumours has proven challenging (Table 1). Widely used senescence markers such as $\mathrm{p} 16^{\mathrm{INK} 4 \mathrm{~A}}$ staining has been detected in prostate cancer cells, complicating the detection and quantification of senescent cells in human prostate cancer tissues. For instance, one study including 104 radical prostatectomy specimens reported increased p16 staining in prostate adenocarcinoma and prostatic intraepithelial neoplasia compared with non-malignant or BPH samples. The intensity of immunostaining was stronger in adenocarcinoma and PIN than adjacent benign or hyperplastic tissue in $86 / 91$ (94.5\%) of samples and $71 / 75$ (94.6\%), respectively ${ }^{31}$. Similarly, tissue microarrays constructed from 80 radical prostatectomy specimens detected positive staining of $\mathrm{p} 16^{\mathrm{INK} 4 \mathrm{~A}}$ in $19 \%$ of prostatic intraepithelial neoplasia (PIN), $25 \%$ of the low-grade carcinoma, and $43 \%$ of the high-grade carcinoma specimens but none in the normal prostate and nodular hyperplasia specimens ${ }^{32}$.

Preclinical mouse models have helped explore the role of senescence in prostate cancer. For example, p53-dependent cellular senescence was shown to be a potent tumour-suppressing mechanism in a PTEN-negative mouse model. Transgenic mice were produced to study the effects of PTEN and/or Trp53 genes inactivation in the prostate. PTEN-negative prostates contained large amounts of senescent cells compared to wild-type mice (\% of cells positive with SA- $\beta$ galactosidase staining $\sim 20 \%$ versus $<1 \%$ ). Loss of Trp53, inactivating cellular senescence, rendered PTEN-negative carcinomas lethal, increasing tumour size and significantly impairing cumulative survival $(p<0.0001)^{33}$. This type of PTEN-loss-induced cellular senescence, unrelated to DNA damage, is distinct from the oncogene-induced senescence pathway and, additionally to being an interesting pre-clinical model of cancerassociated senescence, could provide an interesting target for cancer therapy ${ }^{34}$.

The role of therapy-induced senescence has also been studied in preclinical models. In a cell culture study using LNCaP and LAPC-4 prostate cancer epithelial cell lines, androgen deprivation induced very little apoptosis, but seemed instead to act by inducing senescence, as demonstrated in vitro by increased SA- $\beta$ galactosidase activity and decreased cell proliferation measured by Ki-67 co-staining ${ }^{35}$. These findings were further verified and confirmed in vivo using mice bearing LuCaP xenograft tumours, in which surgical castration led to increased SA- $\beta$ galactosidase staining (from $5 \%$ of tumour cells at baseline to $22 \%$ of tumours 10 days after castration on frozen section of tumour samples) , decreased Ki-67, 
and minor apoptosis detected as cleaved caspase $3^{36}$. Induction of senescence was also demonstrated after chemotherapy. The comparison of the expression of 17 genes increased during the senescence process of human prostate epithelial cells to other growth-inhibitory events such as apoptosis allowed for the definition of a nine-gene panel specific to senescence. Using LNCaP cell lines, a greater than two-fold induction of the senescence gene panel was detected in 30/45 data points after treatment with doxorubicin or docetaxel ${ }^{30}$.

These results highlight that, although they share common signalling pathways, senescencetriggering mechanisms have a variety of origins, including therapy-induced, oncogeneinduced and age-induced senescence. However, whether cells rendered senescent through different mechanisms share the same secretory phenotypes (SASPs) is still unclear. For instance, whether prostatic intraepithelial neoplasia (PIN), a premalignant lesion that has been shown to exhibit senescence markers in a PTEN-negative mouse model, along with a 415 -fold increase in transcript levels of several SASP cytokines (including IL-1 $\alpha$, IL-1 $\beta$ and TNF $\alpha$ ) shares the same SASP as BPH is not known, although both disorders rarely progress to cancer ${ }^{37}$. Furthermore, many studies into prostate cancer senescence were conducted in preclinical models, including mouse models, of which the PTEN-knockout model was the most frequently used ${ }^{38}$. These findings have to be interpreted with caution as previous studies on senescence in tumours have shown that the results obtained with human prostate xenograft models were not easily reproduced in clinical studies in humans ${ }^{39}$. Furthermore, the mouse prostate differs from the human prostate in both morphology and tissue structure. Both arise from the urogenital sinus, and share similar cell composition and molecular characteristics, but while the human prostate forms a single anatomical structure, the mouse prostate is divided into four lobes distributed around the urethra. The main histological difference can be found in the stromal component, less developed in mice ${ }^{40}$.

Clinical studies have mostly considered non-cancerous tissues. In 2000, the first study investigating the presence of senescent cells in the human prostate reported the detection of SA- $\beta$ galactosidase activity in cell cultures obtained from non-cancerous radical prostatectomy specimens and prostate biopsy samples with histologically confirmed BPH. Staining was detected in $43 \%$ of prostatectomy and $31 \%$ of biopsy cultures, exclusively in 
epithelial cells. Interestingly, a strong correlation was found between the presence of SA- $\beta$ galactosidase staining and prostate weight, but no correlation with patient age was observed, suggesting that the amount of senescent cells does not necessarily correlate with age ${ }^{41}$. A subsequent study of senescence in snap-frozen, non-cancerous hyperplastic tissue obtained from radical prostatectomy specimens detected SA- $\beta$ galactosidase staining at least focally in all samples. Focal to extensive staining was noted, depending on patient samples, often displaying multiple foci in each tissue sample. Again no staining was noted in stromal cells ${ }^{42}$.

The presence of senescent epithelial cells in the non-malignant areas of formalin-fixed paraffin-embedded radical prostatectomy specimens was confirmed using cathepsin $D$ and p16 INK4A co-staining. Tissue microarrays were constructed from 7 biopsy cores from normal transition zone tissues, 19 cores from hyperplastic tissues and 2 control cores (all free from prostate cancer) and subsequent quantitative analysis of cathepsin D staining showed a correlation between cathepsin D level and prostate weight as well as, for the first time, staining of stromal cells, albeit to a lesser extent ${ }^{43}$. Immunochemistry staining for p16 $16^{\text {INK4A }}$ was performed in another study using paraffin-embedded sections of prostate BPH specimens obtained from two patients. Many p16-positive epithelial cells were noted, as well as less frequent $\mathrm{p} 16$-positive cells in the prostate stroma ${ }^{44}$. The latter finding is interesting since a differential growth is noted between the stromal and epithelial compartments in symptomatic BPH, and senescent cells were likely to be present also in the stroma ${ }^{45}$.

To explore senescence in malignant tissues, staining of nuclear promyelocytic leukaemia protein (PML) bodies has been used in conjunction with $\mathrm{p} 16^{\mathrm{INK} 4 \mathrm{~A}}$ staining to detect and quantify senescent cells. Seven BPH samples were used, and tissue microarrays were constructed containing 49 cores from normal prostate, 55 cores from tissue adjacent to prostate tumours, 32 cores with PIN and 64 cores from prostate adenocarcinoma. All samples with $\mathrm{BPH}$ displayed strong $\mathrm{p} 16^{\mathrm{INK} 4 \mathrm{~A}}$ staining. PML bodies were found in the epithelial cells of $26.54 \%$ of normal tissue cores, $0 \%$ of PIN, $100 \%$ of BPH samples and $3.13 \%$ of tumours ${ }^{46}$. Phosphorylated ERK (phospho-ERK) has also been used as a senescence marker in combination with $\mathrm{p} 16^{\mathrm{INK} 4 \mathrm{~A}}$ and PML bodies to assess senescence in human normal 
prostate, BPH and prostate cancer samples. BPH tissue displayed very high levels of phospho-ERK, p16 INK4A and PML bodies, confirming the importance of senescence involvement in BPH. ERK activation was also seen in prostate carcinomas, with a lower intensity compared to BPH. Nuclear phospho-ERK levels in epithelial cells were inversely correlated with the Gleason pattern $(P<0.05)^{47}$. These two studies reinforce the idea that senescence plays a central role in BPH, while prostate cancer appears to be less associated to the senescence of epithelial cells. Of note, both studies only considered epithelial cells so no conclusion can be drawn on the presence of senescent cells in the stroma and the potential influence of a senescent stroma on adjacent prostate epithelial cells, likely to be the main role senescence plays in epithelial cancer ${ }^{48}$.

\section{Age-related disease and cellular senescence}

The prostate is the only male organ that shows persistent growth through adulthood. The transition zone, located around the prostatic urethra, will progressively and intermittently grow with age to become the main component of the prostate volume (Figure 1) ${ }^{49}$. This proliferation affects both the glandular (epithelial) and stromal compartments of the prostate and displays a disorganised, chaotic architecture ${ }^{50}$ (Figure 2).

Histological studies have shown a non-proportional increase in glandular epithelium and stroma with increased stromal-to-epithelial ratio in symptomatic enlarged prostates ${ }^{45}$. Stromal and epithelial cell proliferation leads to the formation of nodules. Stromal nodules are characterised by the presence of fibroblastic cells, smooth-muscle cells and immature mesenchymal cells, as well as increased vascularisation and substantial lymphocytic infiltrate, showing analogies with the foetal prostate ${ }^{51}$. The inductive role of the stroma and the response of adult BPH epithelium to stromal influences has supported the 'embryonic reawakening' theory of $\mathrm{BPH}(\operatorname{Box} 1)^{52}$. Interestingly, the senescence pathway has been shown to be activated in vivo as early as in the embryonic urogenital development stage, supporting its ability to promote embryonic-like features in tissues ${ }^{53}$.

The chaotic architecture observed in prostatic nodules with intense proliferation, remodelling, inflammation and embryonic-like features can be seen in other age-related 
diseases, such as osteoarthritis or atherosclerosis ${ }^{54}$. The presence of SA- $\beta$-galactosidasepositive senescent cells has been reported in the adult cartilage of patients suffering from osteoarthritis, whereas no staining was observed in control patients without osteoarthritis 55 . Conversely, the transplantation of senescent cartilage cells into the knee region was capable of inducing an osteoarthritis-like condition in mice ${ }^{17}$. The role of $\mathrm{p} 16^{\mathrm{INK} 4 \mathrm{~A}}$-positive senescent cells in driving the formation of atherosclerotic plaques has also been proven in vivo in mice, whereas the removal of senescent cells using senolytic drugs improved atherosclerosis ${ }^{18,56}$.

\section{Senescence and the 'testosterone paradox'}

Testosterone levels are known to decrease during ageing, with hypogonadal levels of testosterone found in $\sim 30 \%$ of healthy men $>70$ years and $50 \%$ of those $>80$ years in the Baltimore Longitudinal Study on Aging, which included 890 men $^{57}$. As prostatic development and growth are androgen-dependent, a parallel decrease in prostatic diseases could be expected; however, prostate cancer and BPH incidences show the opposite trend ${ }^{3,58}$. In a randomized case-control study nested in the Prostate Cancer Prevention Trial (PCPT), men in the highest quartile of testosterone levels presented with a reduced BPH risk (OR $0.67,95 \% \mathrm{Cl} 0.48-0.93, \mathrm{p}<0.002)^{59,60}$. Similarly, a meta-analysis of 20 studies provided a summary relative risk of prostate cancer for an increase of $5 \mathrm{nmol} / \mathrm{L}$ of testosterone of 0.99 (95\% Cl 0.96-1.02), failing to show a significant increase in prostate cancer risk ${ }^{61}$. A 2019 review discussing animal and human studies offered a potential explanation for this effect by summarising the findings of several studies suggesting that a decrease in serum testosterone levels is associated with an increase in pro-inflammatory cytokines including IL-6, IL-1ß and $\mathrm{TNF} \alpha^{62}$.

Although this effect has not yet been confirmed in humans, the involvement of senescence in the process is very likely. Hence, testosterone appeared to play a protective role against ageing in a mouse model of age-related vascular disease, while reduced testosterone levels were associated with increased cell senescence and vascular remodelling ${ }^{63}$. 


\section{Inflammation and senescence in BPH and prostate cancer}

Cellular senescence creates an inflammatory microenvironment through the accumulation of senescent cells and the SASP ${ }^{11}$. Inflammation, induced by a variety of pathways, is already considered an enabling characteristic of cancer and a contributing factor to diseases such as $\mathrm{BPH}^{64,65}$.

\section{The role of inflammation in $\mathrm{BPH}$}

Defining the baseline inflammatory content in the prostate is challenging as most studies investigating these questions have used samples that are limited by some degree of selection or spectrum bias (for example, specimens from radical prostatectomies or transurethral resections). Furthermore, despite valiant efforts in the field, recent expert consensus on a standardized system for quantifying and classifying inflammation is lacking 66 .

Indeed, acute and chronic prostatitis are common in the adult population with up to $80-90 \%$ of men having some degree of inflammation and around $9 \%$ experiencing prostatitis symptoms over the course of one year ${ }^{67,68}$. An association between the level of inflammation and severity of clinical symptoms has been demonstrated in a comprehensive study of tissue microarrays from 282 patients with BPH, showing that IPSS score (21 versus $12, p=0.02$ ) and prostate volume ( 75 versus $64 c c, p=0.02$ ) were both significantly higher in men with high-grade prostatic inflammation ${ }^{69}$. This relationship between $\mathrm{BPH}$ and inflammation appears to persist even in the presence of prostate tumours: in an autopsy study of 167 prostates, inflammation was found in $67.6 \%$ of specimens and was more prevalent in $\mathrm{BPH}$ tissue compared with normal prostate $(75 \%$ versus $50 \%, \mathrm{p}<0.01)$. However, in glands that harboured both prostate cancer and $\mathrm{BPH}$, chronic inflammation was located in the periphery of BPH nodules only in 11 cases, of cancer foci only in 1 case, of both or neither in 3 and 3 cases, respectively $(p=0.006)^{70}$.

Many experts believe that a cascade of biochemical events (including the secretion of several mediators and cytokines, among which IL-17, IL-6, IL-8, IL-1, TNF $\alpha$ ) eventually results 
in the development of BPH nodules ${ }^{65}$. The MTOPS study (Medical Therapy of Prostatic Symptoms) was a randomised study comparing the long-term risk of BPH progression between men treated with finasteride, doxazosin, a combination of both or a placebo ${ }^{71}$. An ancillary study looked at inflammatory markers in the transition zone biopsies of 859 men enrolled in the MTOPS trial. Four markers for inflammatory cells, CD45 a pan-leukocyte marker, $\mathrm{CD} 4, \mathrm{CD} 8$, and $\mathrm{CD} 68$ for activated macrophages, were used to define the degree of inflammation present in the transition zone, ranging from negligible-mild to severe. The risk of clinical BPH progression for men in the highest tertile of moderate/severe inflammation was doubled compared to men in the lower 2 tertiles combined (HR 2.03, $p=0.001)^{72}$. Interestingly, even if causation still cannot be established, this study confirms the temporal precedence of inflammation before BPH progression.

\section{Inflammation and prostate cancer}

Studies into the inflammatory content of cancerous radical prostatectomy or transurethral resection specimens from living patients have attempted to associate the degree of inflammation with clinical outcome, with conflicting results. One of the earliest papers, from 1994, studied haematoxylin and eosin (H\&E)-stained slides from a very heterogeneous cohort of 325 men treated with various modalities, including prostatectomy, transurethral resection, oestrogens, surgical castration and watchful waiting. Prostatic inflammation was defined based on the amount of tumour infiltrating lymphocytes, graded from 1 - rare or absent, to 3 - dense infiltrate. Men with low levels of prostatic inflammation (grade 1) had a lower 10 -year overall survival (50\% versus 75 and $80 \%$ for grade 2 and 3, respectively, $p=0.0017$ ) and progression-free survival (60\% versus $85 \%$ and $75 \%$ for grade 2 and 3 , respectively, $\mathrm{p}<0.0007)^{73}$. However, in 1999, another group reported that high-grade inflammation was considerably less prevalent in malignant tissue than in adjacent benign tissue compartments and that biochemical-recurrence-free survival was, in fact, shorter in men with heavily inflamed tumours ${ }^{74}$. Since then, studies have reported contrasting results, supporting either an antitumourigenic or protumourigenic role for $\mathrm{T}$ and $\mathrm{B}$ lymphocytes, depending on the soluble mediators secreted and regulation of other immune cells ${ }^{75}$. 
Exactly how inflammation is associated with prostate carcinogenesis is unclear, but, in a similar manner to BPH, oxidative stress in response to infectious agents, environmental toxins or direct injury (for example, due to urine reflux) with subsequent DNA damage have all been proposed as initiating events ${ }^{76,77}$. Furthermore, areas of highly proliferating epithelia (as determined by Ki-67 staining) that are rich in inflammatory cells have been described in the peripheral zone and suggested as precursors of PIN ${ }^{77}$. Proliferative inflammatory atrophy (PIA) and prostatic inflammation have been postulated as a response to injury, whereby a subsequent cascade of genetic alterations - such as MYC overexpression, ETS fusions, GSTP1 methylation, PTEN loss and telomere shortening progressively lead from PIA to PIN and cancer ${ }^{78,79}$. Cellular senescence is likely to be implicated in the process: a strong PTEN-loss-induced cellular senescence response that is associated with PIN has been demonstrated in vivo in mice, whereas, in PTEN-negative tumours, senescent cells can induce infiltration by granulocytic myeloid-derived suppressor cells that render T-cells inactive, suppressing the antitumour immune response ${ }^{80}$.This latter finding is particularly interesting, as increased T-cell density has been associated with PTEN loss (as well as with ERG positivity and TP53 mutations) and poorer outcome in AfricanAmerican men with prostate cancer, with lower biochemical recurrence-free survival (35\% for men with CD3 infiltrate density in the top tertile versus $57 \%$ at 10 years, $p=0.04 ; 14 \%$ for men with CD8 infiltrate density in the top tertile versus $56 \%$ at 10 years, $p=0.04$ ) and metastasis-free survival (64\% at 10 years for men with FOXP3 infiltrate density in the top tertile versus $87 \%, p=0.03)^{81,82}$. Senescent prostate cancer epithelial cells have also shown their ability to alter the composition of laminin chains, which are important components of the extracellular matrix (ECM), linking the ECM to cells through various cell surface receptors and playing an important role in cell migration ${ }^{83}$. Senescent prostate cancer epithelial cell lines (M12 and LNCaP) demonstrated increased mRNA levels of 2 subtypes of LM chains (LM $\alpha 4$ and $\beta 2$ chains), which individually increased the ability of the cancer cells to migrate in vitro (relative migration $\times 1.4$ for $\alpha 4, \times 1.3$ for $\beta 2$ chains, both $p<0.01$ ). These findings were confirmed in vivo in mice, where tumours overexpressing LM $\beta 2$ chains displayed a higher tumour volume at 6 weeks $(250 \mathrm{~mm} 3 \text { versus } 100 \mathrm{~mm} 3, \mathrm{p}<0.01)^{84}$. 


\section{Inflammation, BPH and prostate cancer}

Whether inflammation could, indeed, be a possible link between BPH and prostate cancer, is much more complicated to determine, as both processes are promoted by cytokines that regulate cell growth in a paracrine or autocrine manner ${ }^{7}$. The evidence in this area is conflicting, not least because of a clear detection bias arising from the fact that PSAtriggered sampling is common in men with prostatitis, BPH and cancer. In an interesting study, this bias was substantially reduced by assessing Prostate Cancer Prevention Trial (PCPT) participants without cancer who, after their end-of-study biopsy, immediately enrolled in the Selenium and Vitamin E Cancer Prevention Trial (SELECT) ${ }^{85}$. Most of these men, without evidence of prostate cancer at baseline, had inflammation in their biopsy cores (78.2\% in the placebo arm and $92.4 \%$ in the finasteride arm). During follow-up, for men previously enrolled in the placebo arm of the PCPT, the degree of inflammation present at baseline (end-of-trial PCPT biopsy) was higher for patients later diagnosed with prostate cancer during the SELECT study $(40.4 \%$ of biopsy cores with inflammation at baseline versus $32.1 \%, p<0.05)$. These findings establish for the first time a temporal precedence of inflammation before prostate cancer diagnosis (6 years on average), using a study design where biopsies were not triggered by a high PSA, limiting a potential confusion bias. Of note, these results were not confirmed for previous PCPT participants in the finasteride arm later diagnosed with prostate cancer (38.9\% of biopsy cores with inflammation at baseline for patients later developing prostate cancer versus $35.2 \%$, not significant) ${ }^{85}$. Multiple studies have reported similar findings, linking increased inflammation with increased cancer risk, and, until 2018, prostatitis and cancer were believed to be associated ${ }^{86}$. However, a meta-analysis of 38 studies concluded that, although the odds of cancer after clinical prostatitis are generally increased, they are attenuated if one accounts for detection bias. Indeed, when combining estimates of all studies without considering the potential influence of detection bias, a significant positive association was found between clinical prostatitis and prostate cancer (OR 2.10,95\% $\mathrm{Cl} 1.69-2.61, \mathrm{p}<0.001)$. However, when focusing solely on studies addressing detection bias in various ways (adjustment for prostate cancer screening, estimates restricted to screened men, exclusion of prostatitis in the short window before cancer diagnosis), the association weakened (OR 1.45, 95\% CI 0.98-2.15, not significant) ${ }^{87}$. Of note, 'clinical prostatitis' and 'histological inflammation' are still not 
interchangeable terms, and lack of association in this study does not definitively prove the lack of causality between inflammation and cancer.

\section{Inflammation and senescence}

Prostatic inflammation can be arise through various different means, including infection, toxins, chemical injury or physical injury ${ }^{68,88-90}$. However, senescence is now thought to be involved in the inflammatory process regardless of the origin, both as a consequence of DNA damage caused by these various stimuli and as an amplifying mechanism through SASP 88. Oxidative stress, consecutive to the release of reactive oxygen species (ROS) and reactive nitrogen species, is hypothesised to encourage both direct DNA damage and genetic instability ${ }^{68}$. As a consequence, the senescence pathway is activated, presumably to prevent tumorigenesis in a highly pro-tumourigenic context. In an in vitro model using mouse embryonic fibroblasts deficient for Krüppel-like factor 4 - a factor preventing the accumulation of reactive oxygen species - ROS accumulation was associated with increased level of DNA damage, detected by immunostaining against $\gamma-\mathrm{H} 2 \mathrm{AX}$ (\% of cells with DNA damage $55 \%$ versus $10 \%, p<0.001$ ), as well as the induction of senescence (\% of cells positive for $\mathrm{SA}-\beta$ galactosidase staining $30 \%$ versus $0 \%, \mathrm{p}<0.05)$, through a process involving $\mathrm{p} 21$ and p53 ${ }^{91}$. Senescent cells in turn add to the inflammatory process through the secretion of the various components of the SASP ${ }^{11}$.

\section{SASP contribution to BPH and prostate cancer}

Via SASP, senescent cells contribute to chronic inflammation and an inflammatory environment. Various mediators - including cytokines, chemokines, growth factors and proteases - have been proposed to be a component of SASP (Box 2). SASP can induce senescence in adjacent non-senescent cells via paracrine pathways, which contribute to the inflammatory environment ${ }^{11}$. In addition to its role in $\mathrm{BPH}$, pro-tumourigenic effects of SASP have been documented in prostate cancer (Figure 3).

Several components of the SASP can be linked with the pathogenesis of prostate cancer and $\mathrm{BPH}$. A direct association has been described between senescence and $\mathrm{BPH}$, whereas the evidence supporting a role a role of SASP in prostate cancer could be considered to be 
somewhat circumstantial. Many of the findings obtained from studies in cell cultures and human xenograft mouse models still have to be replicated in humans.

\section{Interleukins}

Although senescence is considered to be a tumour suppression mechanism, a substantial body of evidence supports SASP as driving the pro-tumourigenic effects of senescence ${ }^{11,92}$. Although no direct evidence exists linking senescence-induced IL-6 levels to prostate cancer progression in humans, the role of IL- 6 in the promotion of prostate cancer growth and aggressivity has been well demonstrated in vitro and in vivo, in animal models and prostate cancer patients ${ }^{93}$. In a prospective study, plasma levels of IL-6 and the soluble IL-6 receptor IL-6sR were measured in 120 consecutive patients prior to radical prostatectomy, 44 healthy men without any cancer, 19 men with prostate cancer metastatic to the regional lymph nodes, and 10 men with prostate cancer metastatic to bone. Levels of both IL-6 and IL-6sR were found to be highest in patients with bone metastases $(p<0.001)$, and associated with tumour volume ( $p \leq 0.048)$, final Gleason sum ( $\leq 0.042)$ and risk of progression $(p \leq 0.029)$ in prostatectomy patients ${ }^{94}$. Similarly, a study used tissue microarrays constructed from the radical prostatectomy specimens of 38 men and 26 metastatic tissue samples obtained from 6 men at autopsy to study IL- 6 and IL-8 expression by prostatic cells and the tumour microenvironment using immunohistochemistry and RNA in situ hybridisation. IL-6 mRNA was not detected in tumour cells but instead confined to the stromal compartment. IL-8 was the most abundantly expressed cytokine, and the intensity of IL-8 mRNA signal was significantly higher among high-grade compared to low-grade localised tumours $(p=0.0001)$. Similarly, IL-8 expression was detected in all metastatic sites, and was significantly higher in lung and liver, both visceral metastatic sites involved in aggressive disease $(p<0.005$ and $\mathrm{p}<0.0001$ for lung and liver lesions, respectively) ${ }^{95}$.

Using cell cultures established from the non-malignant peripheral and transition zones of radical prostatectomy specimens, an initial study focusing on BPH showed that prostatic epithelial cells produced IL-1 $\alpha$, inducing FGF7 and resulting in the continuous growth of the transition zone in an autocrine manner. This autocrine stimulation proved critical to the abnormal proliferation of the transition zone and the development of $\mathrm{BPH}^{96}$. Further experiments comparing normal prostatic peripheral zone and BPH tissue by enzyme-linked 
immunosorbent assay (ELISA) showed that the production of IL-8 by epithelial cells induced FGF2 expression by stromal cells, also leading to abnormal proliferation in the transition zone $^{97}$. The link between senescence, IL-8 expression and BPH was later confirmed in a subsequent study using ELISA, showing that tissue IL-8 levels correlated with both SA $\beta$ galactosidase activity $(p<0.01)$ and prostate weight $(p<0.05)^{98}$. These results have to be interpreted with caution, keeping in mind the limitations of SA $\beta$-galactosidase staining in cells with increased activity. Reassuringly, these findings were corroborated by two subsequent studies using other markers to detect senescent cells. The first study assessed in vitro the activation of SASP in senescent prostate BPH-1 cells. The expression of IL-6 $(p=0.015), I L-8(p=0.003), I L-1 \alpha(p=0.0008)$ and IL-1 $\beta(p<0.0001)$ was significantly increased after the onset of senescence, confirmed by $\mathrm{p} 16^{\mathrm{INK} 4 \mathrm{~A}}$ staining ${ }^{44}$. In the second study, samples of normal or hyperplastic transition zone were acquired from radical prostatectomy specimens and checked for the absence of carcinoma. Senescent cells were detected through a combination of SA $\beta$-galactosidase, $\mathrm{p} 16^{\mathrm{INK} 4 \mathrm{~A}}$ and Cathepsin D. IL-8 expression in BPH samples was almost twice as high as normal samples $(p<0.05)$. Of note, staining was again predominantly epithelial ${ }^{43}$.

\section{The TGF $\beta 1$ pathway}

The TGF- $\beta$ pathway has been shown to be a key player in the senescence process, through the stimulation of cell cycle regulators leading to cell cycle arrest (p15, p21, p27), the induction of reactive oxygen species production responsible for DNA damage, and the suppression of telomerase activity involved in telomere shortening ${ }^{99}$. An initial study into the implications of this pathway in BPH used ELISA techniques on 30 prostatectomy specimens obtained in men aged $60-80$ years and described similar expression of TGF- $\beta 1$ in epithelial and stromal cells of both normal and enlarged prostates, but differential expression of its receptor, TGF- $\beta 1 \mathrm{RI}$, resulting in increased TGF- $\beta 1$ activity in BPH samples ${ }^{100}$. Further experiments using human prostate stromal cell cultures demonstrated that fibroblast-to-myofibroblast differentiation was able to drive prostatic stromal growth under TGF- $\beta 1$ stimulation, but proved the inability of TGF- $\beta 1$ to induce senescence, supporting the hypothesis that TGF- $\beta 1$ is secreted by senescent cells rather than it being a senescencedriving mechanism ${ }^{101}$. This result was supported by another study that attempted to induce senescence by application of TGF- $\beta 1$ to cultures of human multipotent mesenchymal 
stromal cells. Cells cultured in the presence of TGF- $\beta 1$ displayed a different growth pattern (network-like versus a more homogeneous cellular layer), an increased proliferation and entered replicative senescence on average 46 days earlier $(p=0.05)$. However, after adjusting for the higher number of cell divisions due to increased proliferation, no significant increase in the amount of senescent cells (detected by SA $\beta$-galactosidase staining) was noted after TGF- $\beta 1$ stimulation $(p>0.05){ }^{102}$. Furthermore, further support for this mechanism came from a study that used a mouse model of human BPH, in which TGF- $\beta 1$ was hypothesised to recruit mesenchymal/stromal stem cells to the stroma during prostatic hyperplasia. The activation of the TGF- $\beta$ pathway and increased TGF- $\beta 1$ concentration in the plasma of BPH mice models compared with controls was demonstrated $(p<0.01)$. This study also investigated the expression of TGF- $\beta$ in human BPH specimens, confirming that high levels of TGF- $\beta$ activity were associated with stromal expansion in the pathogenesis of human $\mathrm{BPH}^{103}$. Further work by the same team provided more insight into the TGF- $\beta 1$-induced transformation of prostate stromal cells into myofibroblasts. By first looking at the differential expression of several long non-coding RNAs and genes under TGF- $\beta 1$ stimulation using prostate stromal cells cultures, they were able to identify one long non-coding RNA, DNM3OS, and the gene most prominent for upregulation, COL3A1. Both were found to be overexpressed, as well as TGF- $\beta 1$ (DNM3OS relative expression $2, p<0.05$; COL3A1 1.5, $p<0.01$; TGF- $\beta 1, p<0.01)$ in human BPH samples $(n=20)$ compared to controls consisting of normal prostate tissue obtained from cystoprostatectomy specimens $(n=5)$. ${ }^{104}$. The role of TGF- $\beta 1$ in EMT of prostate epithelial cells was further supported by an in vitro study using a human BPH cell line (BPH-1). When exposed to stromal cells culture media obtained from human prostatic stromal myofibroblast cell line (WPMY-1), BPH-1 cells displayed reduced expression of epithelial markers (E-cadherin and CK5/8), positive expression of mesenchymal markers (vimentin, a-SMA) and the EMT marker Snail, and increased migratory capacity. This induction of EMT was inhibited by anti-TGF- $\beta 1$ treatment, confirming the important role of TGF- $\beta 1$ in the process ${ }^{105}$.

TGF- $\beta$ has also been implicated in the promotion and progression of cancers, including prostate cancer ${ }^{106}$. Analysis of normal prostate, PIN and prostate cancer tissue obtained from radical prostatectomy specimens, frozen prostate biopsy cores and a prostate cancer tissue microarray by immunochemistry demonstrated that PIN cells expressed higher levels of TGF- $\beta 1$ than normal prostate tissue This increased expression was associated with the 
presence of a reactive stroma, assessed by vimentin and $\alpha$-actin staining, increased to moderate/high levels in $48 \%$ of PIN cases ( $p<0.001$; Fisher's exact test) compared to normal prostate tissue ${ }^{107}$. TGF- $\beta 1$ further proved crucial in prostate fibroblast-to-myofibroblast differentiation in another study using cell cultures established from radical prostatectomy specimens ( $n=3)$. TGF- $\beta 1$-stimulated cells displayed $\alpha$-actin, calponin and tenascin staining, markers of a myofibroblast/smooth muscle cell phenotype ${ }^{101}$. Furthermore, in a study involving 68 prostate cancer patients treated by surgery, radiation and/or chemotherapy, and 62 healthy volunteers, plasma levels of TGF- $\beta 1$ were significantly upregulated among prostate cancer patients $(p<0.05)$. Additionally, prostate cancer cell migration and invasion was increased in vitro after treatment with exogenous TGF- $\beta 1{ }^{108}$. Interestingly, the therapeutic potential of TGF- $\beta$ signalling inhibition has been demonstrated in vivo in a preclinical mouse model of prostate tumour progression (transgenic adenocarcinoma of mouse prostate - TRAMP model). Galunisertib, a TGF- $\beta$ receptor I inhibitor, was administered with enzalutamide, and the antitumoral effect of the combination compared to monotherapy with enzalutamide or galunisertib, or controls. Prostate tumours were harvested and analysed on Day 15. A significant reduction in tumour weight was noted for the combination compared to galunisertib alone and controls. Although a difference was noted between the combination and enzalutamide alone, it was not statistically significant. Reversal of EMT and re-differentiation was also noted in prostate tumours exposed to TGF- $\beta$ inhibition ${ }^{109}$. Finally, Dickkopf-related protein 3 (DKK3), which has been implicated in many age-related diseases such as Alzheimer's disease, skeletal muscle atrophy or kidney disease, was found to regulate TGF- $\beta$-dependent activity of MMP-2 and MMP-9, promoting prostate cancer cell migration and invasion ${ }^{110}$.

\section{CXCL-12 and CXCL-1}

Epithelial-stromal interactions are crucial to the regulation of prostate epithelial cell growth, and the influence of SASP - specifically CXCL-12 and CXCL-1 - has been identified in both BPH and prostate cancer ${ }^{111,112}$.

Senescent stromal fibroblasts obtained from the prostates of older patients (63-72 years) demonstrated a reduced ability to limit in vitro epithelial cell proliferation compared with 
senescent stromal fibroblasts from younger men (40-52 years) (average cell number 235990 ( \pm 14680 ) versus 142000 ( \pm 16400$), p<0.001)^{111}$. In the same study, higher levels of secretion of CXCL12 were noted in fibroblasts from the older men compared with younger fibroblasts. This expression of CXCL12 protein was associated with increased epithelial cell proliferation, as is observed in human $\mathrm{BPH}^{111}$.

The paracrine mechanisms modulating epithelial cell proliferation were explored in a separate study using stromal fibroblasts obtained from the non-cancerous regions of radical prostatectomy specimens. This in vitro study demonstrated that senescent fibroblasts were capable of influencing the survival and proliferation of neoplastic adjacent prostate epithelium, via mechanisms involving CXCL-1, MMP-2 and FGF7. Direct co-culture of epithelial cells with senescent fibroblasts resulted in a 3-fold growth of epithelial cells, while culture with conditioned medium from senescent prostate fibroblasts increased epithelial cell proliferation of 3-fold ${ }^{112}$. Tumour stroma has also been implicated in the carcinogenesis of adjacent BPH epithelium. Via the secretion of CXCL-12, prostatic cancer-associated fibroblasts (CAFs) were able to induce tumorigenesis in non-malignant human prostatic epithelial cells (BPH-1) in vitro. This mechanism was found to be dependent on the presence of TGF- $\beta$ in vivo in a mouse model, although not directly linked with senescence ${ }^{113}$.

\section{Extracellular vesicles and microRNAs as elements of the SASP}

Extracellular vesicles are essential components of inter-cellular communication; by releasing their cargo into recipient cells, and through surface molecules, they can influence and regulate their function. Extracellular vesicles can contain proteins, lipids, DNA, mRNA and non-coding RNA, including short non-coding RNAs or microRNA (miRNA) ${ }^{114}$. The content of extracellular vesicles has been explored in urological malignancies including prostate cancer, as a potential biomarker, prognostic factor or even therapeutic drug vehicle ${ }^{115}$. MiRNAs can alter gene expression by post-transcriptional regulation of mRNA and, therefore, have an important regulation role, including in cell-cycle regulation and therefore also in senescence ${ }^{104}$. Consequently, the role of miRNA in both cancer and ageing has garnered considerable interest. Notably, several miRNAs that are dysregulated during ageing - such as miR-106 and miR-30 families, which are both known to interact with the $\mathrm{p} 16^{\mathrm{INK} 4 \mathrm{~A}} / \mathrm{Rb}$ pathway - are also dysregulated in prostate cancer ${ }^{116,117}$. 
The potential role of extracellular vesicles released by senescent cells in cancer initiation and progression has led to their consideration as part of SASP ${ }^{118}$. Particularly relevant to prostate cancer, both therapy-induced (through external irradiation) and replicative senescence have been demonstrated to cause an increased release of exosome-like microvesicles and that these vesicles express $\mathrm{B} 7-\mathrm{H} 3$, a protein proposed as a potential prognostic biomarker to distinguish indolent from aggressive prostate cancer ${ }^{119}$. These findings support the hypothesis that extracellular vesicles are increasingly released during senescence and that the content of these vesicles might promote prostate cancer progression and aggressiveness. Other studies have further explored the content and function of extracellular vesicles' cargo during ageing, although without focusing on prostate cancer. Isolation of extracellular vesicles from the plasma of young and old mice illustrated an increase in extracellular vesicle levels and differential miRNA expression. Increased expression of miR-146a, miR-21, miR-22, miR-223, miR-145 and let-7a within the extracellular vesicles of old mice was confirmed in an independent sample set $(n=6$, all $p<0.05)$. In the same study, the exposition of young macrophages to old extracellular vesicles resulted in an increased expression of TGF- $\beta 1$, whose role has been previously assessed in senescence and prostatic diseases ${ }^{120}$. Additionally, miR-21 had already been explored in prostate cancer and found to be significantly upregulated in the blood and urine of prostate cancer patients compared with healthy subjects ${ }^{121,122}$. However, whether extracellular vesicles have a role in the induction of senescence in adjacent prostatic cells remains unclear.

\section{Senescence and cancer-associated fibroblasts}

The role of fibroblasts and their transformation into myofibroblasts with a wound repair phenotype was first described in the early $2000 s^{107}$. These fibroblasts, now referred to as cancer-associated fibroblasts (CAFs), share several common features with ageing fibroblasts, including similar cell morphology and a secretory phenotype ${ }^{123}$. A study using CAFs extracted from radical prostatectomy specimens confirmed their role in inducing invasiveness of prostate cancer cell in vitro via a mechanism involving IL-6, a cytokine that is strongly associated with SASP ${ }^{124}$. 
Cathepsin D, another marker of senescence, was also reported as an essential mediator of CAF-induced tumourigenicity in vivo. Tissue recombinants were engineered combining initiated but non-malignant BPH-1 cell line with normal prostate fibroblasts, or with CAFs obtained from human prostate tumour samples. These recombinants were then grafted under the kidney capsule of adult male severe combined immunodeficient. CAFs proved their ability to induce tumourigenesis of $\mathrm{BPH}-1$, and this transformation was inhibited when cathepsin D expression was knocked down (tumour volume 16cc versus $1 c c, p<0.05$ ) ${ }^{25}$. Another study of in vitro co-culture of CAFs isolated from prostate cancer patients and prostate cancer cell lines (PC-3 and LNCaP) demonstrated that CAFs regulate proliferation and migration of prostate cancer cells via TGF- $\beta 1$ signalling ${ }^{125}$. Subsequently, CAFs were shown to recruit myeloid cells and guide immune cell recruitment around benign BPH cells via the release of chemokines such as CCL-2 and CXCL-12, contributing to the inflammatory microenvironment ${ }^{126}$. Of note, both of these chemokines have also been linked to senescence and cancer progression, although only the role of CXCL-12 has been established in prostate cancer as a key mediator used by CAFs to induce tumourigenicity in adjacent epithelial cells ${ }^{113,127}$.

\section{Pro-tumourigenic intracellular signalling induction by SASP}

The pro-tumourigenic effects of SASP are mediated by a range of intracellular signalling pathways, in particular the PI3K-AKT, JAK-STAT, RAS and MAPK pathways ${ }^{44}$. These well characterised signal transduction networks are highly interconnected, with complex crosstalk, feedback mechanisms and compensatory signalling enabling both activation and regulation of key oncogenic phenotypes (Figure 4). Several of these pathways can be activated in response to SASP in a pro-tumourigenic manner and also have a role in the induction of senescence itself. An example of this is Pim-1, which acts in both a protumourigenic capacity downstream of JAK-STAT signalling and is also a key player in the mediation of senescence, responsible for the formation of a chromatin architecture associated with senescence (heterochromatin) and the suppression of proliferative genes ${ }^{128}$. Similarly, ERK activation seems to have a role both in oncogenesis and tumour suppression by triggering cellular senescence, notably by enhancing the degradation of multiple proteins required for cell-cycle progression ${ }^{129}$. 


\section{Clinical implications}

The theory of senescence as a potential mechanism triggering or amplifying the pathological processes involved in BPH and prostate cancer has potential clinical and therapeutic implications. The cellular volume generated by the accumulation of senescent cells could contribute to the increased prostate volume in $\mathrm{BPH}$, as suggested by the correlation found between the presence of senescent cells and prostate weight ${ }^{41}$. The pro-tumourigenic effects of SASP and its contribution to BPH have been documented.

Senolytic agents aim at selectively removing senescent cells without causing damage to normal cells, by specifically targeting cells displaying hallmarks of senescence such as SA- $\beta$ galactosidase expression, or signalling pathways activated during the senescence process ${ }^{130}$. Apoptosis resistance is a common characteristic shared by senescent cells and cancer cells. Consequently, targeted cancer therapeutic agents against anti-apoptotic proteins, such as $\mathrm{Bcl}-2$ inhibitors, used in lymphoma, display senolytic properties ${ }^{130}$. Preliminary results have shown potential benefits in terms of prolonged lifespan and reduced onset of age-related physical dysfunction in mice treated with the senolytic association of dasatinib and quercetin ${ }^{17}$. Old mice, as well as young mice subjected to premature ageing via the transplantation of senescent cells both benefited from systemic oral administration of the association, with an increased post-treatment survival $(+36 \%)$ and a reduced mortality hazard $(65 \%, p=0.01){ }^{17}$. However, these studies are very preliminary and the results might not be reproducible in humans. Furthermore, the systemic administration of senolytic drugs exposes the recipient to side-effects secondary to the destruction of non-senescent cells, or potential side-effects of the removal of senescent cells ${ }^{130}$.

The reason for the persistence of senescent cells through evolution remains unknown, although they are very likely to have a role in providing structure to tissues that could otherwise not be maintained owing to reduced cellular replication, such as brain or adipose tissue ${ }^{9}$. Senescent cells can account for more than $50 \%$, and up to $90 \%$ of all epithelial cells, therefore their removal could have deleterious implications for the structure of the tissue ${ }^{41}$. However, surgery and medical treatments aiming at partially removing the prostate driving 
prostatic tissue atrophy have been long used without serious adverse effects and the selective removal of intraprostatic senescent cells is, therefore, unlikely to be associated with serious adverse events compared with reduction in cellular volume of other organs or systems such as the brain or cardiovascular system .

Agents targeting SASP components - SASP inhibitors or senomorphics - could also be of interest, and could have a potential dual effect on both BPH and prostate cancer. Among potential senomorphic drugs, a four-day course of the oral p38 MAP kinase inhibitor Losmapimod was shown to reduce plasma levels of IL-6 and TNF- $\alpha(p<0.0001)$ in 18 aged healthy volunteers (65-77 years, median 69 years), without affecting the removal of the senescent cells themselves, restoring the cutaneous immunity against varicella zoster virus altered during ageing ${ }^{131}$.

Monoclonal antibodies targeting IL-1 $\alpha$, IL- 6 or IL- 8 are being tested in age-related diseases such as type 2 diabetes - improving C-peptide and HbA1c levels- and osteoarthritis reducing pain and inducing a pro-regenerative cartilage environment ${ }^{132}$.

Cancer-associated fibroblasts are a key element of the tumour microenvironment and could provide new therapeutic targets ${ }^{133}$. The similarities of the phenotypes displayed by senescent fibroblasts and cancer-associated fibroblasts are remarkable, and it is very likely that senescence pathways are involved in the interactions between CAFs and the adjacent epithelia. Senolytic drugs, or drugs inhibiting SASP components known to be critical in the induction of tumourigenesis such as IL-6, could be tested as a new therapeutic approach targeting the tumour microenvironment.

Therapy-induced senescent cells in prostate cancer have also been proposed as therapeutic targets. Mammalian target of rapamycin (mTOR) inhibitors have shown their interest in reducing SASP components. Senescent adult human prostate fibroblasts (PSC27) were exposed to rapamycin, and displayed reduced IL-6 secretion in vitro (relative IL-6 level reduced by $\sim 80 \%)$. These results were confirmed in vivo in mice xenografts, in which treatment with rapamycin suppressed the ability of senescent fibroblasts to stimulate prostate tumour growth (tumour grafts volume $296 \mathrm{~mm}^{3}$ with rapamycin versus $589 \mathrm{~mm}^{3}$, $\mathrm{p}<0.01)^{134}$. In another study, xenografts were generated from human prostate cancer LNCaP 
and PC-3 cells and injected to male nude mice, before mice were treated with either docetaxel, the mTOR inhibitor temsirolimus, or a combination of both (concurrent or sequential administration). Concurrent treatment with temsirolimus and docetaxel proved more effective to delay tumour regrowth than sequential treatment (mean tumour volume at day 52 of $167 \pm 32 \mathrm{~mm}^{3}$ versus $461 \pm 114 \mathrm{~mm}^{3}, \mathrm{p}=0.038$ ), and more effective than docetaxel or temsirolimus alone. ${ }^{135}$. Androgen deprivation was also shown to induce senescence, detected using SA- $\beta$ galactosidase staining, in LNCaP prostate cancer cells cultured in androgen-free medium. The percentage of cells positive for SA- $\beta$ galactosidase staining increased to $60 \%$ after 9 days of androgen deprivation, while the global number of cells decreased by $50 \%$. Further experiments were performed to confirm these findings in vivo by establishing androgen-sensitive xenograft tumours (LuCap 58 and 23.1) in athymic nude mice. The proportion of cells positive for SA- $\beta$ galactosidase staining increased from $5 \%$ prior to castration to $22 \%(p<0.001)^{36}$.

The modulation of the tissue microenvironment by senescent cells was even proposed as a plausible mechanism of the evolution of prostate cancer towards androgen-independence. Several components of the SASP such as IL- 6 and IL-8, released by senescence cells in a paracrine manner, are indeed capable of overriding the need for androgen ligand and therefore stimulating the clonal expansion of androgen-independent cells ${ }^{35}$. Thus, targeting senescence might also prove beneficial in patients treated with ADT.

\section{Grey areas and open questions}

The available evidence and studies providing insight, and often comprehension, of the mechanisms involved provide biological plausibility for the association of cellular senescence, inflammation, BPH and prostate cancer. However, causation still remains to be demonstrated. Co-occurrence of increased senescence and cancer in the ageing organism might be simply a consequence of an accumulation of events occurring over time, rather than one phenomenon explaining the other. Many results obtained using cell cultures and mouse models have not been replicated in humans, and caution must be observed when interpreting these findings. Similarly, data have been obtained in other organs, such as cartilage, skin or other cancers, we have to acknowledge that these findings should only be 
considered as hypothesis-generating as they still have to be reproduced in prostate or prostate cancer and that different cancer types can react differently to exogenous stimuli or use different intracellular pathways is well known.

Some pathological processes, such as BPH and osteoarthritis, have been linked to cellular senescence but not to patient age ${ }^{41,55}$. Although these data could lead to the rejection of ageing and senescence as a causative mechanism, not all individuals age in the same way and time elapsed, in itself, is not a sufficient marker of ageing ${ }^{136}$. The frontier between normal, physiological ageing and age-related diseases is not well defined, and accurate biomarkers for both ageing and senescence are needed ${ }^{136}$.

In prostate cancer, research into the presence of senescent cells in specimens obtained from patients with prostate cancer is crucial, as senescent cells have been identified mostly in the epithelium, whereas the role of senescence and SASP seems to be played mostly through the influence of a senescent stroma on adjacent epithelial cells ${ }^{48}$. Although no evidence indicates that low-grade prostate cancer should be considered as a normal ageing process, the intensity of SASP signalling and the aggressivity of cancer do seem to be associated ${ }^{137}$. Longitudinal studies - including, for example, biobank specimens harvested at various timepoints - would be needed to corroborate biological plausibility and causality. The follow-up monitoring of patients and the evolution of the amount and distribution of senescent cells throughout the trial could be key to understanding the potential causative role of senescence in both $\mathrm{BPH}$ and prostate cancer.

\section{Conclusions}

Growing evidence supports the presence of senescent cells in the prostate and the existence of shared senescence signalling pathways in the promotion of BPH. Further studies are needed to confirm the presence and role of senescent cells in prostate cancer, and longitudinal studies - including, for example, biobank specimens harvested at various timepoints - could help corroborate biological plausibility and causality. The removal of senescent cells using senolytic treatments and/or the reduction of the SASP with SASP inhibitors or senomorphics present new therapeutic opportunities that might prevent and control the onset of $\mathrm{BPH}$ and prostate cancer. 


\section{Key points}

- Benign prostatic hyperplasia (BPH) and prostate cancer are two common disorders affecting the prostate and both share an increased incidence with advancing age.

- Ageing, along with other sources of cellular damage (infection, infection, toxins, chemical or physical injury), results in cellular senescence and the accumulation of senescent cells in tissues

- Senescent cells, although unable to replicate, remain metabolically active and secrete a raft of inflammatory mediators, known as senescence-associated secretory phenotype (SASP)

- Senescent cells have been detected using senescence markers in almost all human samples of $\mathrm{BPH}$, and the role of several components of the SASP established in BPH initiation and progression.

- The role of cellular senescence in prostate cancer is less clearly established, and senescence seems to act mainly through the influence of the senescent stroma on adjacent epithelial cells, favouring cancer initiation, progression and metastasis.

- The demonstration of the role of senescence in both age-related prostatic diseases presents new therapeutic opportunities with treatments aiming at removing senescent cells (senolytics) and/or targeting components of the SASP (SASP inhibitors or senomorphics).

\section{Acknowledgements}

Gaelle Fiard receives funding from the Fondation de France and the European Urology Scholarship Program. Vasilis Stavrinides is supported by an MRC Clinical Research Training Fellowship (MR/S005897/1), the Mason Medical Research Foundation (project number: 558866) and acknowledges previous support from The Alan Turing Institute (EPSRC grant EP/N510129/1), the EACR (EACR Travel Fellowship) and UCL (Bogue Fellowship). Emma S chambers is funded by a Barts Charity Lectureship (grant MGU045). Susan Heavey is supported by a Movember-funded Prostate Cancer UK fellowship, TLD-PF16-004. Arne Akbar is supported by the Medical Research Council (MR/P00184X/1) and an MRC Grand Challenge 
in Experimental Medicine Grant (MR/M003833/1). Mark Emberton receives research support from the United Kingdom's National Institute of Health Research (NIHR) UCLH/UCL Biomedical Centre. He was conferred NIHR Senior Investigator status in 2015.

1. Berry, S. J., Coffey, D. S., Walsh, P. C. \& Ewing, L. L. The development of human benign prostatic hyperplasia with age. J. Urol. 132, 474-479 (1984).

2. Soos, G. et al. The prevalence of prostate carcinoma and its precursor in Hungary: an autopsy study. Eur. Urol. 48, 739-744 (2005).

3. Bell, K. J. L., Del Mar, C., Wright, G., Dickinson, J. \& Glasziou, P. Prevalence of incidental prostate cancer: A systematic review of autopsy studies. Int. J. Cancer 137, 17491757 (2015).

4. McNeal, J. E. The zonal anatomy of the prostate. The Prostate 2, 35-49 (1981).

5. McNeal, J. E., Redwine, E. A., Freiha, F. S. \& Stamey, T. A. Zonal distribution of prostatic adenocarcinoma. Correlation with histologic pattern and direction of spread. Am.J. Surg. Pathol. 12, 897-906 (1988).

6. Turkbey, B. et al. Age-related changes in prostate zonal volumes as measured by highresolution magnetic resonance imaging (MRI): a cross-sectional study in over 500 patients. BJU Int. 110, 1642-1647 (2012).

7. De Nunzio, C. et al. The controversial relationship between benign prostatic hyperplasia and prostate cancer: the role of inflammation. Eur. Urol. 60, 106-117 (2011).

8. Cai, T. et al. Current Knowledge of the Potential Links between Inflammation and Prostate Cancer. Int. J. Mol. Sci. 20, (2019).

9. van Deursen, J. M. The role of senescent cells in ageing. Nature 509, 439-446 (2014). 10. Hayflick, L. \& Moorhead, P. S. The serial cultivation of human diploid cell strains. Exp. Cell Res. 25, 585-621 (1961).

11. Coppé, J.-P., Desprez, P.-Y., Krtolica, A. \& Campisi, J. The senescence-associated secretory phenotype: the dark side of tumor suppression. Annu. Rev. Pathol. 5, 99-118 (2010).

12. Campisi, J. \& d'Adda di Fagagna, F. Cellular senescence: when bad things happen to good cells. Nat. Rev. Mol. Cell Biol. 8, 729-740 (2007).

13. Franceschi, C. \& Campisi, J. Chronic inflammation (inflammaging) and its potential contribution to age-associated diseases. J. Gerontol. A. Biol. Sci. Med. Sci. 69 Suppl 1, S4-9 (2014).

14. Huda, N. et al. Hepatic senescence, the good and the bad. World J. Gastroenterol. 25, 5069-5081 (2019).

15. $\mathrm{Xu}, \mathrm{M}$. et al. Transplanted Senescent Cells Induce an Osteoarthritis-Like Condition in Mice. J. Gerontol. A. Biol. Sci. Med. Sci. 72, 780-785 (2017).

16. Baker, D. J. et al. Clearance of p16Ink4a-positive senescent cells delays ageingassociated disorders. Nature 479, 232-236 (2011).

17. $\mathrm{Xu}, \mathrm{M}$. et al. Senolytics improve physical function and increase lifespan in old age. Nat. Med. 24, 1246-1256 (2018).

18. Roos, C. M. et al. Chronic senolytic treatment alleviates established vasomotor dysfunction in aged or atherosclerotic mice. Aging Cell 15, 973-977 (2016).

19. Yousefzadeh, M. J. et al. Fisetin is a senotherapeutic that extends health and lifespan. EBioMedicine 36, 18-28 (2018).

20. Adamus, J., Aho, S., Meldrum, H., Bosko, C. \& Lee, J.-M. p16INK4A influences the aging phenotype in the living skin equivalent. J. Invest. Dermatol. 134, 1131-1133 (2014).

21. Waaijer, M. E. C. et al. The number of p16INK4a positive cells in human skin reflects 
biological age. Aging Cell 11, 722-725 (2012).

22. Dimri, G. P. et al. A biomarker that identifies senescent human cells in culture and in aging skin in vivo. Proc. Natl. Acad. Sci. U. S. A. 92, 9363-9367 (1995).

23. Smith, J. R. \& Pereira-Smith, O. M. Replicative senescence: implications for in vivo aging and tumor suppression. Science 273, 63-67 (1996).

24. Byun, H.-O. et al. Cathepsin D and eukaryotic translation elongation factor 1 as promising markers of cellular senescence. Cancer Res. 69, 4638-4647 (2009).

25. Pruitt, F. L. et al. Cathepsin D acts as an essential mediator to promote malignancy of benign prostatic epithelium. The Prostate 73, 476-488 (2013).

26. Kuilman, T., Michaloglou, C., Mooi, W. J. \& Peeper, D. S. The essence of senescence. Genes Dev. 24, 2463-2479 (2010).

27. Biran, A. et al. Quantitative identification of senescent cells in aging and disease. Aging Cell 16, 661-671 (2017).

28. Childs, B. G., Bussian, T. J. \& Baker, D. J. Cellular Identification and Quantification of Senescence-Associated $\beta$-Galactosidase Activity In Vivo. Methods Mol. Biol. Clifton NJ 1896, 31-38 (2019).

29. Pereira, B. I. et al. Senescent cells evade immune clearance via HLA-E-mediated NK and CD8+ T cell inhibition. Nat. Commun. 10, 2387 (2019).

30. Schwarze, S. R., Fu, V. X., Desotelle, J. A., Kenowski, M. L. \& Jarrard, D. F. The identification of senescence-specific genes during the induction of senescence in prostate cancer cells. Neoplasia N. Y. N 7, 816-823 (2005).

31. Halvorsen, O. J., Haukaas, S., Høisæter, P. Å. \& Akslen, L. A. Expression of p 16 protein in prostatic adenocarcinomas, intraepithelial neoplasia, and benign/hyperplastic glands. Urol. Oncol. 3, 59-66 (1997).

32. Zhang, Z., Rosen, D. G., Yao, J. L., Huang, J. \& Liu, J. Expression of p14ARF, p15INK4b, p16INK4a, and DCR2 increases during prostate cancer progression. Mod. Pathol. Off. J. U. S. Can. Acad. Pathol. Inc 19, 1339-1343 (2006).

33. Chen, Z. et al. Crucial role of p53-dependent cellular senescence in suppression of Pten-deficient tumorigenesis. Nature 436, 725-730 (2005).

34. Alimonti, A. et al. A novel type of cellular senescence that can be enhanced in mouse models and human tumor xenografts to suppress prostate tumorigenesis. J. Clin. Invest. 120, 681-693 (2010).

35. Pernicová, Z. et al. Androgen depletion induces senescence in prostate cancer cells through down-regulation of Skp2. Neoplasia N. Y. N 13, 526-536 (2011).

36. Ewald, J. A. et al. Androgen deprivation induces senescence characteristics in prostate cancer cells in vitro and in vivo. The Prostate 73, 337-345 (2013).

37. Parisotto, M. et al. PTEN deletion in luminal cells of mature prostate induces replication stress and senescence in vivo. J. Exp. Med. 215, 1749-1763 (2018).

38. Hensley, P. J. \& Kyprianou, N. Modeling prostate cancer in mice: limitations and opportunities. J. Androl. 33, 133-144 (2012).

39. Collado, M. \& Serrano, M. Senescence in tumours: evidence from mice and humans. Nat. Rev. Cancer 10, 51-57 (2010).

40. Oliveira, D. S. M. et al. The mouse prostate: a basic anatomical and histological guideline. Bosn. J. Basic Med. Sci. 16, 8-13 (2016).

41. Choi, J. et al. Expression of senescence-associated beta-galactosidase in enlarged prostates from men with benign prostatic hyperplasia. Urology 56, 160-166 (2000).

42. Castro, P., Giri, D., Lamb, D. \& Ittmann, M. Cellular senescence in the pathogenesis of benign prostatic hyperplasia. The Prostate 55, 30-38 (2003).

43. Vital, P., Castro, P., Tsang, S. \& Ittmann, M. The senescence-associated secretory phenotype promotes benign prostatic hyperplasia. Am. J. Pathol. 184, 721-731 (2014). 
44. Jiang, S., Song, C. S. \& Chatterjee, B. Stimulation of Prostate Cells by the Senescence Phenotype of Epithelial and Stromal Cells: Implication for Benign Prostate Hyperplasia.

FASEB BioAdvances 1, 353-363 (2019).

45. Shapiro, E., Becich, M. J., Hartanto, V. \& Lepor, H. The relative proportion of stromal and epithelial hyperplasia is related to the development of symptomatic benign prostate hyperplasia. J. Urol. 147, 1293-1297 (1992).

46. Vernier, M. et al. Regulation of E2Fs and senescence by PML nuclear bodies. Genes Dev. 25, 41-50 (2011).

47. Deschênes-Simard, X. et al. Tumor suppressor activity of the ERK/MAPK pathway by promoting selective protein degradation. Genes Dev. 27, 900-915 (2013).

48. Krtolica, A. \& Campisi, J. Integrating epithelial cancer, aging stroma and cellular senescence. Adv. Gerontol. Uspekhi Gerontol. 11, 109-116 (2003).

49. McNeal, J. E. Origin and evolution of benign prostatic enlargement. Invest. Urol. 15, 340-345 (1978).

50. Untergasser, G., Madersbacher, S. \& Berger, P. Benign prostatic hyperplasia: agerelated tissue-remodeling. Exp. Gerontol. 40, 121-128 (2005).

51. Bierhoff, E. et al. Morphological analogies of fetal prostate stroma and stromal nodules in BPH. The Prostate 31, 234-240 (1997).

52. Cunha, G. R. \& Ricke, W. A. A historical perspective on the role of stroma in the pathogenesis of benign prostatic hyperplasia. Differ. Res. Biol. Divers. 82, 168-172 (2011).

53. Muñoz-Espín, D. et al. Programmed cell senescence during mammalian embryonic development. Cell 155, 1104-1118 (2013).

54. Felka, T. et al. Loss of spatial organization and destruction of the pericellular matrix in early osteoarthritis in vivo and in a novel in vitro methodology. Osteoarthritis Cartilage 24, 1200-1209 (2016).

55. Price, J. S. et al. The role of chondrocyte senescence in osteoarthritis. Aging Cell 1, 57-65 (2002).

56. Childs, B. G. et al. Senescent intimal foam cells are deleterious at all stages of atherosclerosis. Science 354, 472-477 (2016).

57. Harman, S. M. et al. Longitudinal effects of aging on serum total and free testosterone levels in healthy men. Baltimore Longitudinal Study of Aging. J. Clin. Endocrinol. Metab.

86, 724-731 (2001).

58. Roehrborn, C. G., Marks, L. \& Harkaway, R. Enlarged prostate: A landmark national survey of its prevalence and impact on US men and their partners. Prostate Cancer Prostatic Dis. 9, 30-34 (2006).

59. Thompson, I. M. et al. The influence of finasteride on the development of prostate cancer. N. Engl. J. Med. 349, 215-224 (2003).

60. Kristal, A. R. et al. Serum steroid and sex hormone-binding globulin concentrations and the risk of incident benign prostatic hyperplasia: results from the prostate cancer prevention trial. Am. J. Epidemiol. 168, 1416-1424 (2008).

61. Boyle, P. et al. Endogenous and exogenous testosterone and the risk of prostate cancer and increased prostate-specific antigen (PSA) level: a meta-analysis. BJU Int. 118, 731-741 (2016).

62. Mohamad, N.-V. et al. The relationship between circulating testosterone and inflammatory cytokines in men. Aging Male Off. J. Int. Soc. Study Aging Male 22, 129-140 (2019).

63. Chen, Y.-Q. et al. Testosterone ameliorates vascular aging via the Gas6/Axl signaling pathway. Aging 12, 16111-16125 (2020).

64. Hanahan, D. \& Weinberg, R. A. Hallmarks of Cancer: The Next Generation. Cell 144, 646-674 (2011). 
65. De Nunzio, C., Presicce, F. \& Tubaro, A. Inflammatory mediators in the development and progression of benign prostatic hyperplasia. Nat. Rev. Urol. 13, 613-626 (2016).

66. Nickel, J. C. et al. Consensus development of a histopathological classification system for chronic prostatic inflammation. BJU Int. 87, 797-805 (2001).

67. Nickel, J. C. Prostatitis. Can. Urol. Assoc. J. 5, 306-315 (2011).

68. Sfanos, K. S., Yegnasubramanian, S., Nelson, W. G. \& De Marzo, A. M. The inflammatory microenvironment and microbiome in prostate cancer development. Nat. Rev.

Urol. 15, 11-24 (2018).

69. Robert, G. et al. Inflammation in benign prostatic hyperplasia: A 282 patients' immunohistochemical analysis. The Prostate 69, 1774-1780 (2009).

70. Delongchamps, N. B. et al. Evaluation of prostatitis in autopsied prostates--is chronic inflammation more associated with benign prostatic hyperplasia or cancer? J. Urol. 179, 1736-1740 (2008).

71. McConnell, J. D. et al. The long-term effect of doxazosin, finasteride, and combination therapy on the clinical progression of benign prostatic hyperplasia. N. Engl. J. Med. 349, 2387-2398 (2003).

72. Torkko, K. C. et al. Prostate Biopsy Markers of Inflammation are Associated with Risk of Clinical Progression of Benign Prostatic Hyperplasia: Findings from the MTOPS Study. J. Urol. 194, 454-461 (2015).

73. Vesalainen, S., Lipponen, P., Talja, M. \& Syrjänen, K. Histological grade, perineural infiltration, tumour-infiltrating lymphocytes and apoptosis as determinants of long-term prognosis in prostatic adenocarcinoma. Eur. J. Cancer 30, 1797-1803 (1994).

74. Irani, J. et al. High-grade inflammation in prostate cancer as a prognostic factor for biochemical recurrence after radical prostatectomy. Urology 54, 467-472 (1999).

75. Rani, A., Dasgupta, P. \& Murphy, J. J. Prostate Cancer: The Role of Inflammation and Chemokines. Am. J. Pathol. 189, 2119-2137 (2019).

76. Sfanos, K. S., Yegnasubramanian, S., Nelson, W. G. \& De Marzo, A. M. The inflammatory microenvironment and microbiome in prostate cancer development. Nat. Rev. Urol. 15, 11-24 (2017).

77. De Marzo, A. M. et al. Inflammation in prostate carcinogenesis. Nat. Rev. Cancer 7, 256-269 (2007).

78. De Marzo, A. M., Haffner, M. C., Lotan, T. L., Yegnasubramanian, S. \& Nelson, W. G. Premalignancy in Prostate Cancer: Rethinking What We Know. Cancer Prev. Res. (Phila. Pa.) 9, 648-656 (2016).

79. Gerrin, S. J., Sowalsky, A. G., Balk, S. P. \& Ye, H. Mutation Profiling Indicates High Grade Prostatic Intraepithelial Neoplasia as Distant Precursors of Adjacent Invasive Prostatic Adenocarcinoma: Mutation Profile of HGPIN. The Prostate 76, 1227-1236 (2016).

80. Toso, A. et al. Enhancing Chemotherapy Efficacy in Pten -Deficient Prostate Tumors by Activating the Senescence-Associated Antitumor Immunity. Cell Rep. 9, 75-89 (2014).

81. Kaur, H. B. et al. Association of tumor-infiltrating T-cell density with molecular subtype, racial ancestry and clinical outcomes in prostate cancer. Mod. Pathol. (2018) doi:10.1038/s41379-018-0083-x.

82. Kaur, H. B. et al. TP53 missense mutation is associated with increased tumorinfiltrating T cells in primary prostate cancer. Hum. Pathol. 87, 95-102 (2019).

83. Patarroyo, M., Tryggvason, K. \& Virtanen, I. Laminin isoforms in tumor invasion, angiogenesis and metastasis. Semin. Cancer Biol. 12, 197-207 (2002).

84. Sprenger, C. C. T. et al. Senescence-induced alterations of laminin chain expression modulate tumorigenicity of prostate cancer cells. Neoplasia N. Y. N 10, 1350-1361 (2008).

85. Platz, E. A. et al. A Prospective Study of Chronic Inflammation in Benign Prostate Tissue and Risk of Prostate Cancer: Linked PCPT and SELECT Cohorts. Cancer Epidemiol. 
Biomarkers Prev. 26, 1549-1557 (2017).

86. Jiang, J. et al. The role of prostatitis in prostate cancer: meta-analysis. PloS One $\mathbf{8}$, e85179 (2013).

87. Langston, M. E. et al. A Systematic Review and Meta-analysis of Associations between Clinical Prostatitis and Prostate Cancer: New Estimates Accounting for Detection Bias. Cancer Epidemiol. Biomarkers Prev. 28, 1594-1603 (2019).

88. de Bono, J. S. et al. Prostate carcinogenesis: inflammatory storms. Nat. Rev. Cancer 20, 455-469 (2020).

89. Shinohara, D. B. et al. A mouse model of chronic prostatic inflammation using a human prostate cancer-derived isolate of Propionibacterium acnes. The Prostate 73, 1007 1015 (2013).

90. Kirby, R. S., Lowe, D., Bultitude, M. I. \& Shuttleworth, K. E. Intra-prostatic urinary reflux: an aetiological factor in abacterial prostatitis. Br. J. Urol. 54, 729-731 (1982).

91. Liu, C., La Rosa, S. \& Hagos, E. G. Oxidative DNA damage causes premature senescence in mouse embryonic fibroblasts deficient for Krüppel-like factor 4. Mol.

Carcinog. 54, 889-899 (2015).

92. Wang, B., Kohli, J. \& Demaria, M. Senescent Cells in Cancer Therapy: Friends or Foes? Trends Cancer 6, 838-857 (2020).

93. Nguyen, D. P., Li, J. \& Tewari, A. K. Inflammation and prostate cancer: the role of interleukin 6 (IL-6). BJU Int. 113, 986-992 (2014).

94. Shariat, S. F. et al. Plasma levels of interleukin-6 and its soluble receptor are associated with prostate cancer progression and metastasis. Urology 58, 1008-1015 (2001). 95. Maynard, J. P. et al. IL8 Expression Is Associated with Prostate Cancer Aggressiveness and Androgen Receptor Loss in Primary and Metastatic Prostate Cancer. Mol. Cancer Res. MCR 18, 153-165 (2020).

96. Giri, D. \& Ittmann, M. Interleukin-1alpha is a paracrine inducer of FGF7, a key epithelial growth factor in benign prostatic hyperplasia. Am. J. Pathol. 157, 249-255 (2000).

97. Giri, D. \& Ittmann, M. Interleukin-8 is a paracrine inducer of fibroblast growth factor 2, a stromal and epithelial growth factor in benign prostatic hyperplasia. Am. J. Pathol. 159, 139-147 (2001).

98. Castro, P., Xia, C., Gomez, L., Lamb, D. J. \& Ittmann, M. Interleukin-8 expression is increased in senescent prostatic epithelial cells and promotes the development of benign prostatic hyperplasia. The Prostate 60, 153-159 (2004).

99. Tominaga, K. \& Suzuki, H. I. TGF- $\beta$ Signaling in Cellular Senescence and AgingRelated Pathology. Int. J. Mol. Sci. 20, (2019).

100. Royuela, M. et al. Transforming growth factor beta 1 and its receptor types I and II. Comparison in human normal prostate, benign prostatic hyperplasia, and prostatic carcinoma. Growth Factors Chur Switz. 16, 101-110 (1998).

101. Untergasser, G. et al. Profiling molecular targets of TGF-beta1 in prostate fibroblastto-myofibroblast transdifferentiation. Mech. Ageing Dev. 126, 59-69 (2005).

102. Walenda, G. et al. TGF-betal does not induce senescence of multipotent mesenchymal stromal cells and has similar effects in early and late passages. PloS One 8, e77656 (2013).

103. Wang, L. et al. Aberrant Transforming Growth Factor- $\beta$ Activation Recruits Mesenchymal Stem Cells During Prostatic Hyperplasia. Stem Cells Transl. Med. 6, 394-404 (2017).

104. Wang, R. et al. Long noncoding RNA DNM3OS promotes prostate stromal cells transformation via the miR-29a/29b/COL3A1 and miR-361/TGF $\beta 1$ axes. Aging 11, 94429460 (2019).

105. $\mathrm{Hu}, \mathrm{S}$. et al. Evidence of TGF- $\beta 1$ mediated epithelial-mesenchymal transition in immortalized benign prostatic hyperplasia cells. Mol. Membr. Biol. 31, 103-110 (2014). 
106. Elliott, R. L. \& Blobe, G. C. Role of transforming growth factor Beta in human cancer. J. Clin. Oncol. Off. J. Am. Soc. Clin. Oncol. 23, 2078-2093 (2005).

107. Tuxhorn, J. A. et al. Reactive stroma in human prostate cancer: induction of myofibroblast phenotype and extracellular matrix remodeling. Clin. Cancer Res. Off. J. Am. Assoc. Cancer Res. 8, 2912-2923 (2002).

108. Zhang, H. et al. lncRNA MIR4435-2HG promotes cancer cell migration and invasion in prostate carcinoma by upregulating TGF- $\beta 1$. Oncol. Lett. 18, 4016-4021 (2019).

109. Paller, C. et al. TGF- $\beta$ receptor I inhibitor enhances response to enzalutamide in a preclinical model of advanced prostate cancer. The Prostate 79, 31-43 (2019).

110. Romero, D. et al. Dickkopf-3 regulates prostate epithelial cell acinar morphogenesis and prostate cancer cell invasion by limiting TGF- $\beta$-dependent activation of matrix metalloproteases. Carcinogenesis 37, 18-29 (2016).

111. Begley, L., Monteleon, C., Shah, R. B., Macdonald, J. W. \& Macoska, J. A. CXCL12 overexpression and secretion by aging fibroblasts enhance human prostate epithelial proliferation in vitro. Aging Cell 4, 291-298 (2005).

112. Bavik, C. et al. The gene expression program of prostate fibroblast senescence modulates neoplastic epithelial cell proliferation through paracrine mechanisms. Cancer Res. 66, 794-802 (2006).

113. Ao, M. et al. Cross-talk between paracrine-acting cytokine and chemokine pathways promotes malignancy in benign human prostatic epithelium. Cancer Res. 67, 4244-4253 (2007).

114. Linxweiler, J. \& Junker, K. Extracellular vesicles in urological malignancies: an update. Nat. Rev. Urol. 17, 11-27 (2020).

115. Junker, K., Heinzelmann, J., Beckham, C., Ochiya, T. \& Jenster, G. Extracellular Vesicles and Their Role in Urologic Malignancies. Eur. Urol. 70, 323-331 (2016).

116. Valentino, A. et al. Exosomal microRNAs in liquid biopsies: future biomarkers for prostate cancer. Clin. Transl. Oncol. Off. Publ. Fed. Span. Oncol. Soc. Natl. Cancer Inst. Mex. 19, 651-657 (2017).

117. Urbanelli, L., Buratta, S., Sagini, K., Tancini, B. \& Emiliani, C. Extracellular Vesicles as New Players in Cellular Senescence. Int. J. Mol. Sci. 17, (2016).

118. Jakhar, R. \& Crasta, K. Exosomes as Emerging Pro-Tumorigenic Mediators of the Senescence-Associated Secretory Phenotype. Int. J. Mol. Sci. 20, (2019).

119. Lehmann, B. D. et al. Senescence-Associated Exosome Release from Human Prostate Cancer Cells. Cancer Res. 68, 7864-7871 (2008).

120. Alibhai, F. J. et al. Cellular senescence contributes to age-dependent changes in circulating extracellular vesicle cargo and function. Aging Cell e13103 (2020)

doi:10.1111/acel.13103.

121. Yaman Agaoglu, F. et al. Investigation of miR-21, miR-141, and miR-221 in blood circulation of patients with prostate cancer. Tumour Biol. J. Int. Soc. Oncodevelopmental Biol. Med. 32, 583-588 (2011).

122. Foj, L. et al. Exosomal and Non-Exosomal Urinary miRNAs in Prostate Cancer Detection and Prognosis. The Prostate 77, 573-583 (2017).

123. Elkhattouti, A., Hassan, M. \& Gomez, C. R. Stromal Fibroblast in Age-Related Cancer: Role in Tumorigenesis and Potential as Novel Therapeutic Target. Front. Oncol. 5, (2015).

124. Giannoni, E. et al. Reciprocal activation of prostate cancer cells and cancer-associated fibroblasts stimulates epithelial-mesenchymal transition and cancer stemness. Cancer Res. 70, 6945-6956 (2010).

125. Sun, D.-Y., Wu, J.-Q., He, Z.-H., He, M.-F. \& Sun, H.-B. Cancer-associated fibroblast regulate proliferation and migration of prostate cancer cells through TGF- $\beta$ signaling 
pathway. Life Sci. 235, 116791 (2019).

126. Vickman, R. E. et al. Heterogeneity of human prostate carcinoma-associated fibroblasts implicates a role for subpopulations in myeloid cell recruitment. The Prostate 80, 173-185 (2020).

127. Liu, Y. et al. Klotho-mediated targeting of CCL2 suppresses the induction of colorectal cancer progression by stromal cell senescent microenvironments. Mol. Oncol. 13, 2460-2475 (2019).

128. Jin, B. et al. PIM-1 modulates cellular senescence and links IL-6 signaling to heterochromatin formation. Aging Cell 13, 879-889 (2014).

129. Deschênes-Simard, X., Kottakis, F., Meloche, S. \& Ferbeyre, G. ERKs in cancer: friends or foes? Cancer Res. 74, 412-419 (2014).

130. van Deursen, J. M. Senolytic therapies for healthy longevity. Science 364, 636-637 (2019).

131. Vukmanovic-Stejic, M. et al. Enhancement of cutaneous immunity during aging by blocking p38 mitogen-activated protein (MAP) kinase-induced inflammation. J. Allergy Clin. Immunol. 142, 844-856 (2018).

132. von Kobbe, C. Targeting senescent cells: approaches, opportunities, challenges. Aging 11, 12844-12861 (2019).

133. Chen, X. \& Song, E. Turning foes to friends: targeting cancer-associated fibroblasts. Nat. Rev. Drug Discov. 18, 99-115 (2019).

134. Laberge, R.-M. et al. MTOR regulates the pro-tumorigenic senescence-associated secretory phenotype by promoting IL1A translation. Nat. Cell Biol. 17, 1049-1061 (2015). 135. Fung, A. S., Wu, L. \& Tannock, I. F. Concurrent and sequential administration of chemotherapy and the Mammalian target of rapamycin inhibitor temsirolimus in human cancer cells and xenografts. Clin. Cancer Res. Off. J. Am. Assoc. Cancer Res. 15, 5389-5395 (2009).

136. Sprott, R. L. Biomarkers of aging and disease: introduction and definitions. Exp. Gerontol. 45, 2-4 (2010).

137. Coppé, J.-P. et al. Senescence-associated secretory phenotypes reveal cellnonautonomous functions of oncogenic RAS and the p53 tumor suppressor. PLoS Biol. 6, 2853-2868 (2008).

138. Brennen, W. N. \& Isaacs, J. T. Mesenchymal stem cells and the embryonic reawakening theory of BPH. Nat. Rev. Urol. 15, 703-715 (2018).

139. Hayward, S. W., Cunha, G. R. \& Dahiya, R. Normal development and carcinogenesis of the prostate. A unifying hypothesis. Ann. N. Y. Acad. Sci. 784, 50-62 (1996). 
Table 1| Studies evaluating the presence of senescent cells in the human prostate.

\begin{tabular}{|c|c|c|c|c|c|}
\hline Marker & Specimen & Pathology & $\begin{array}{l}\text { Senescent cells } \\
\text { presence }\end{array}$ & $\begin{array}{l}\text { Cellular } \\
\text { location }\end{array}$ & Reference \\
\hline $\begin{array}{l}\text { SA- } \beta \\
\text { galactosidase }\end{array}$ & $\begin{array}{l}\text { Snap-frozen } \\
\text { RP and } \\
\text { prostate } \\
\text { biopsy }\end{array}$ & $\mathrm{BPH}$ & $\begin{array}{l}43 \% \text { of RP } \\
\text { specimens and } \\
31 \% \text { of biopsy } \\
\text { samples }\end{array}$ & Epithelial cells & 41 \\
\hline $\begin{array}{l}\text { SA- } \beta \\
\text { galactosidase }\end{array}$ & $\begin{array}{l}\text { Snap-frozen } \\
\text { RP }\end{array}$ & $\mathrm{BPH}$ & All samples & Epithelial cells & 42 \\
\hline $\begin{array}{l}\text { SA- } \beta \\
\text { galactosidase } \\
\text { Cathepsin D } \\
\text { p16 }\end{array}$ & FFPE RP & $\begin{array}{l}\text { BPH } \\
\text { Non-hyperplastic } \\
\text { prostate tissue) }\end{array}$ & Not stated & $\begin{array}{l}\text { Epithelial cells } \\
>\text { stroma }\end{array}$ & 43 \\
\hline $\begin{array}{l}\text { SA- } \beta \\
\text { galactosidase } \\
\text { p16 }\end{array}$ & $\begin{array}{l}\text { FFPE BPH } \\
\text { samples }\end{array}$ & $\mathrm{BPH}$ & All samples & $\begin{array}{l}\text { Epithelial cells } \\
>\text { stroma }\end{array}$ & 44 \\
\hline $\begin{array}{l}\text { PML bodies } \\
\text { p16 }\end{array}$ & $\begin{array}{l}\text { FFPE BPH } \\
\text { samples } \\
\text { Tissue } \\
\text { microarrays }\end{array}$ & $\begin{array}{l}\text { BPH } \\
\text { Normal prostate } \\
\text { Normal adjacent to } \\
\text { tumours } \\
\text { PIN } \\
\text { Prostate cancer }\end{array}$ & $\begin{array}{l}\text { BPH: } 100 \% \\
\text { Normal: } 26.54 \% \\
\text { (positive for } \\
\text { PML) } \\
\text { Normal } \\
\text { adjacent: } 0 \% \\
\text { PIN: 0\% } \\
\text { Prostate cancer: } \\
3.13 \%\end{array}$ & Epithelial cells & 46 \\
\hline $\begin{array}{l}\text { Phospho-ERK } \\
\text { p16 } \\
\text { PMK4A } \\
\text { PModies }\end{array}$ & $\begin{array}{l}\text { FFPE BPH } \\
\text { samples } \\
\text { Tissue } \\
\text { microarrays }\end{array}$ & $\begin{array}{l}\text { BPH } \\
\text { Normal prostate } \\
\text { Normal adjacent to } \\
\text { tumours } \\
\text { Prostate cancer }\end{array}$ & $\begin{array}{l}\text { BPH: All } \\
\text { samples, High } \\
\text { levels } \\
\text { Normal: Not } \\
\text { stated } \\
\text { Normal } \\
\text { adjacent: Lower } \\
\text { levels* } \\
\text { Prostate cancer: } \\
\text { Lower levels* } \\
\text { *compared to } \\
\text { BPH }\end{array}$ & Epithelial cells & 47 \\
\hline
\end{tabular}

$\mathrm{BPH}$, benign prostatic hyperplasia; FFPE, formalin-fixed, paraffin-embedded; Phospho-ERK, phosphorylated ERK; PML, promyelocytic leukaemia protein; PIN, prostatic intraepithelial neoplasia; RP, radical prostatectomy; SA, senescence-associated;) 
Fig 1

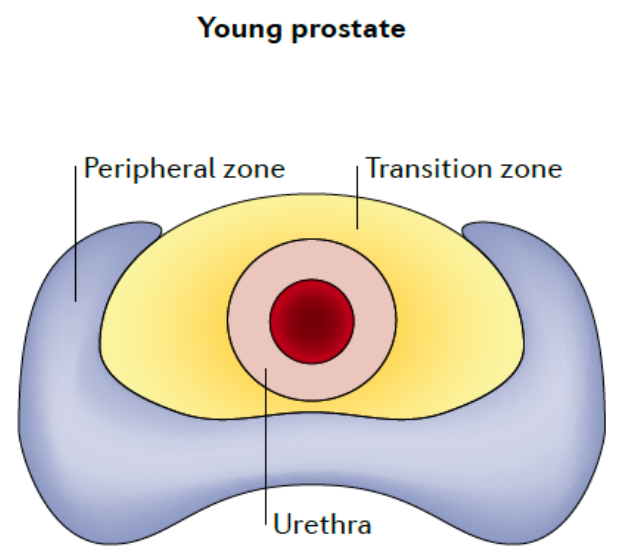

Ageing, hypertrophied prostate

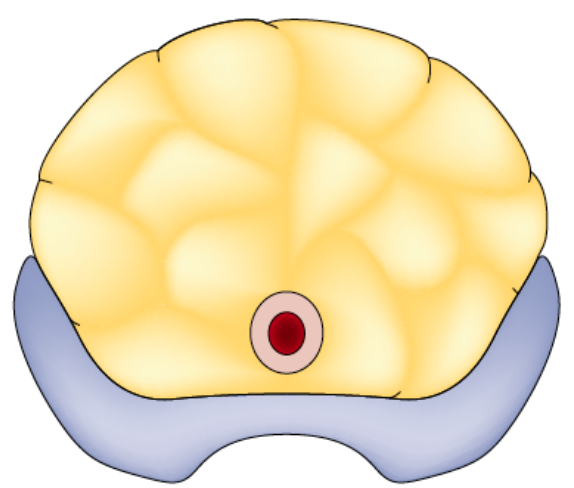

Figure 1 | Differences between the young and ageing hypertrophied prostate. The transition zone occupies a very small volume in the young prostate and its architecture seems normal, whereas its volume is considerably increased in the hypertrophied prostate, in which the transition zone displays a chaotic, nodular architecture. The volume of the peripheral zone remains stable, but with ageing it becomes laminated by the volume of the transition zone.

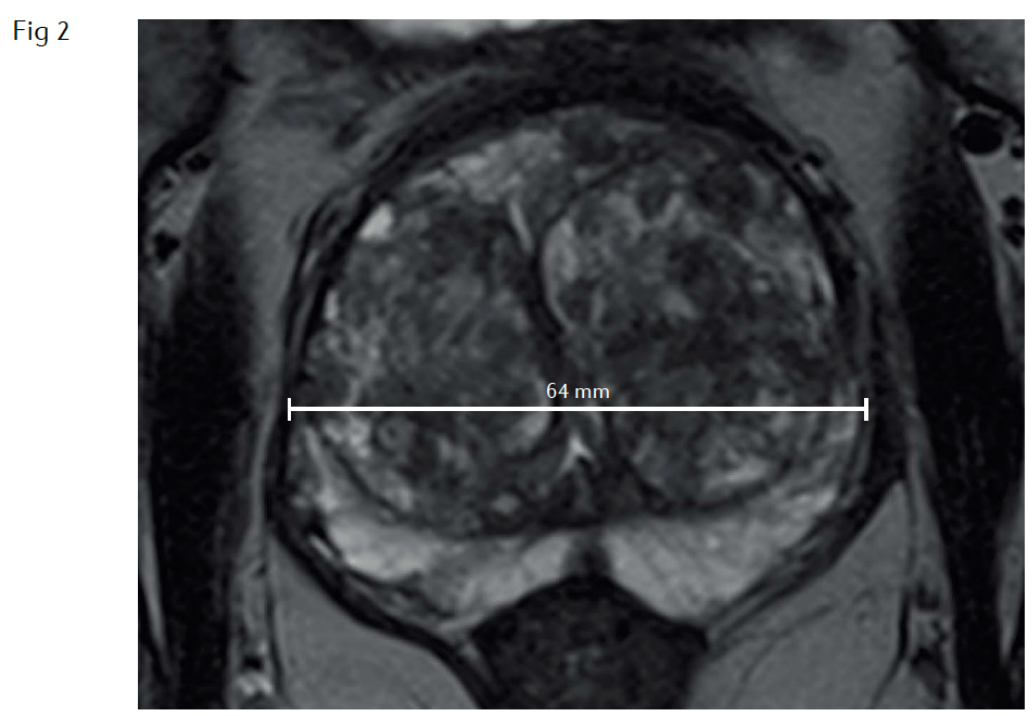

Figure 2| T2-weighted prostate MRI showing the chaotic, nodular architecture of the enlarged transition zone from a 72-year-old patient with symptomatic benign prostatic hyperplasia (BPH) before any kind of treatment. 
Fig 3

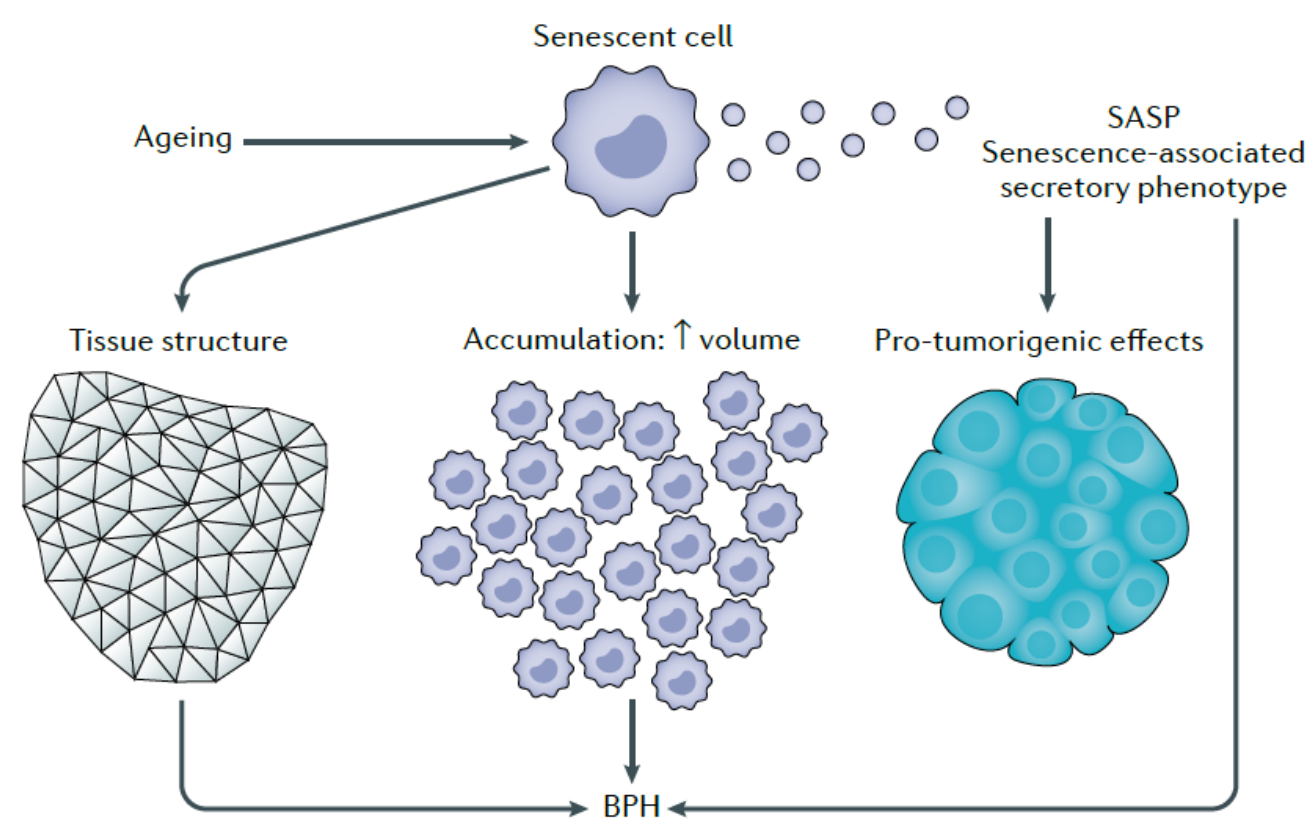

Figure 3 | The implications of senescent cells in benign prostatic hyperplasia (BPH) and prostate cancer. Cells become senescent in response to ageing (replicative senescence) or other cellular damage (such as through treatment with chemotherapy/radiotherapy). Senescent cells are unable to replicate, blocked in the G1 phase of the cell cycle, but are metabolically active, secreting various inflammatory mediators, which form the senescenceassociated secretory phenotype (SASP). As senescent cells accumulate, increased fibrosis, disorganised tissue architecture, macroscopic modifications of organ structure and decreased organ function can be noted. 


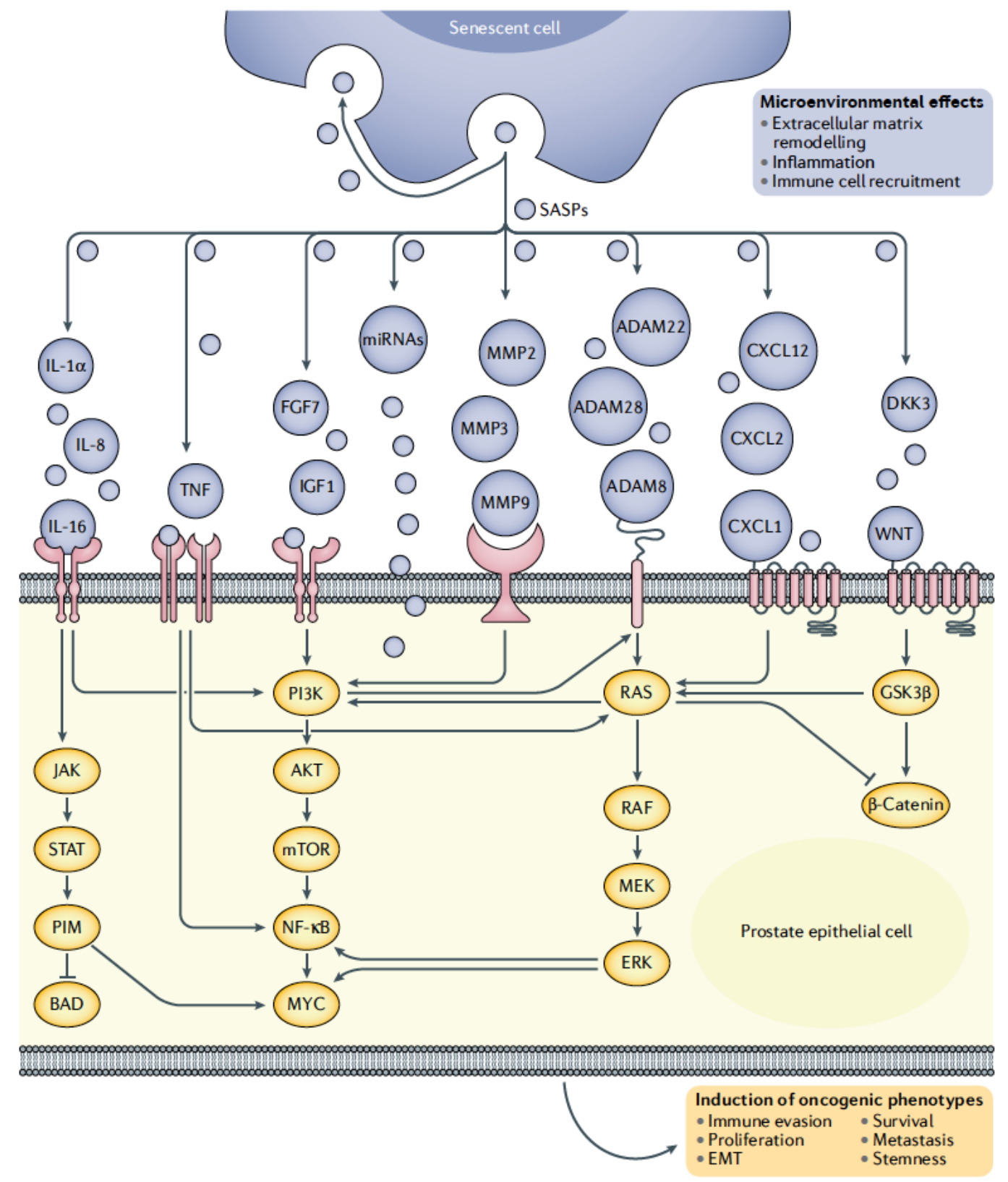

Figure 4 | Key signal transducers activated by the senescence-associated secretory phenotype (SASP). A wide range of cytokines, chemokines, growth factors and proteases have been identified as part of the SASP. Each of these activate prostate cell signalling, typically by binding to cell surface receptors and activating common pro-tumorigenic pathways suck as PI3K, JAK/STAT and MAPK. As with all cell signalling, multiple layers of cross-talk and feedback loops enable flexibility and redundancy for the cell, and several of these proteins, including PIM1, NFKB and ERK 1/2, can both activate and be activated by the SASP. (IL-interleukin; TNF-tumour necrosis factor; FGF-fibroblast growth factor; IGF-insulinlike growth factor, miRNA-microRNA; MMP-matrix metalloproteinase; ADAM-a disintegrin 
and metalloproteinas; DKK-Dickkopf-related protein; WNT- Wingless-related integration site; PI3K- Phosphatidylinositol 3-kinase; JAK-Janus kinase; STAT-Signal Transducer and Activator of Transcription; PIM- proviral integration site for Moloney murine leukemia virus; AKTprotein kinase B, mTOR-mammalian target of rapamycin; NFKB-nuclear factor-kappa B; RASrat sarcoma; RAF-rapidly accelerated fibrosarcoma; MEK- mitogen-activated protein kinase kinase; ERK-extracellular-signal-regulated kinase; GSK3- $\beta$-Glycogen synthase kinase 3 beta; EMT-epithelial-mesenchymal transition)

Box 1 | The 'embryonic reawakening' theory of BPH

The prostate is the only organ that continues to grow in the adult man. According to the 'embryonic reawakening' theory, the onset of BPH is a consequence of the reactivation of an inductive prostate stroma in the transition zone, leading to the recruitment of mesenchymal stem cells to promote tissue repair. This reactivation, responsible for the 'reawakening' of prostate epithelial stem cells and subsequent localised proliferation, happens in response to various stimuli including exposition to urine components or autoantigens ${ }^{138}$. The influx of progenitors, located just outside these smooth muscle fibres at the bladder neck level, can explain the disruption of the periurethral smooth muscle fibres, an essential step in the development of BPH nodules ${ }^{49,139}$.

Box 2 | The senescence-associated secretory phenotype.

A number of mediators are proposed to be a component of the senescence-associated secretory phenotype (SASP). These mediators can be broadly separated into the following categories:

\section{Cytokines}

Pro-inflammatory cytokines, including IL-6, IL $1 \alpha$, IL-1 $\beta$ and TNF $\alpha$, are released by senescent cells and participate in the regulation of the inflammatory reaction and immune response.

\section{Chemokines}

Chemokines are able to influence inflammatory cell migration, which in turn contributes to the inflammatory microenvironment. Overexpression of IL-8, CCL-2, CXCL-1 and CXCL-12, among others including CCL-1, $-3,-7,-8,-13,-16,-20,-26$ and $C X C L-2,-4,-5,-6$, has been documented in senescent cells.

\section{Growth factors}

This family of mediators includes FGF and IGF, both of which are involved in the growth of stromal (FGF) and epithelial (FGF and IGF) compartments in BPH.

\section{Proteases}


Proteases, including matrix metalloproteinases (MMP-1,-3, -10, -12, -13, -14), disintegrins and metalloproteinases (ADAMs8,22,28) are important components of SASP. With their ability to degrade extracellular matrix but also influence cell proliferation, migration and differentiation, they have an important role in cancer progression.

\section{Other}

Other mediators include active lipid compounds and glycoproteins, such as Prostaglandin E2 and Fibronectin, both contributing to an inflammatory state. 